09,04

\title{
Эволюция спектральных и структурных характеристик ортоборатов $\mathrm{La}_{0.98-x} \mathrm{Lu}_{x} \mathrm{Eu}_{0.02} \mathrm{BO}_{3}$
}

\author{
() С.З. Шмурак, В.В. Кедров, А.П. Киселев, Т.Н. Фурсова, И.И. Зверькова, С.С. Хасанов \\ Институт ффизики твердого тела им. Ю.А. Осипьяна РАН, \\ Черноголовка, Россия \\ E-mail: shmurak@issp.ac.ru
}

Поступила в Редакцию 21 июля 2021 г.

В окончательной редакции 21 июля 2021 г.

Принята к публикации 23 июля 2021 г.

\begin{abstract}
Проведены исследования структуры, ИК-спектров поглощения, спектров люминесценции и спектров возбуждения люминесценции синтезированных при $970^{\circ} \mathrm{C}$ ортоборатов $\mathrm{La}_{0.98-x} \mathrm{Lu}_{x} \mathrm{Eu}_{0.02} \mathrm{BO}_{3}$ при $0 \leq x \leq 0.98$. Увеличение $x$ приводит к последовательному изменению структурного состояния ортоборатов. Вначале соединение имеет структуру арагонита, затем становится двухфазным и содержит фазы арагонита и ватерита. При дальнейшем увеличении $x$ соединения имеют структуру ватерита, затем ватерита и кальцита и, наконец, структуру кальцита. Установлено соответствие между структурой и спектральными характеристиками этих соединений. Исследованы спектры люминесценции при разных длинах волн возбуждающего света, что позволило получить информацию о структуре приповерхностного слоя и объема микрокристаллов исследованных образцов. Показано, что фаза ватерита появляется в объеме микрокристаллов образцов, имеющих структуру арагонита.
\end{abstract}

Ключевые слова: люминофоры для светодиодов, ортобораты редкоземельных элементов, рентгенофазовый анализ, ИК-спектроскопия, спектры люминесценции.

DOI: 10.21883/FTT.2021.12.51677.172

\section{1. Введение}

В последние годы большое количество работ посвящено исследованиям спектральных и структурных характеристик молибдатов, вольфраматов, гранатов и боратов, легированных ионами редкоземельных элементов. Интерес к этим соединениям связан с тем, что они являются эффективными люминофорами и могут быть использованы в светодиодных источниках света [1-11]. Для получения различных оттенков „белого“ света крайне важно направленным образом управлять спектральными характеристиками люминофоров. Одним из наиболее эффективных методов направленного изменения спектра излучения полиморфных люминофоров является изменение их структурного состояния, так как каждой структурной модификации молибдатов, вольфраматов и боратов, содержащих оптически активные центры, соответствует характерный только для нее спектр люминесценции (СЛ). Например, в спектре люминесценции кальцитной модификации $\mathrm{LuBO}_{3}(\mathrm{Eu})$ наблюдаются две узкие полосы с $\lambda_{\max } \sim 590$ и $596 \mathrm{~nm}$, в то время как СЛ ватеритной структуры $\mathrm{LuBO}_{3}(\mathrm{Eu})$ содержит ряд линий, сгруппированных в три полосы в области длин волн 593, 611 и $628 \mathrm{~nm}[1-3,12,13]$. По этой причине для кальцитной модификации $\mathrm{LuBO}_{3}(\mathrm{Eu})$ характерно оранжевое свечение, а для ватеритной структуры красное.

Значительные изменения спектров люминесценции ионов $\mathrm{Eu}^{3+}$ при изменении структуры люминофора позволяют использовать ионы $\mathrm{Eu}^{3+}$ в качестве струк- турно-чувствительных и оптически активных меток для идентификации структурного состояния боратов редкоземельных элементов. Как известно, редкоземельные ионы $-\mathrm{RE}^{3+}$ (в том числе и $\mathrm{Eu}^{3+}$ ) чувствительны к ближайшему окружению $[14,15]$. Поэтому по изменению спектральных характеристик $\mathrm{RE}^{3+}$-ионов можно судить об изменении их локального окружения. Ионы $\mathrm{Eu}^{3+}$ позволяют следить за структурным состоянием как в объеме, так и на поверхности образца. Информацию о ближайшем окружении ионов $\mathrm{Eu}^{3+}$ в объеме кристалла можно получить, возбуждая люминесценцию ионов $\mathrm{Eu}^{3+}$ светом с энергией, соответствующей резонансному возбуждению ионов $\mathrm{Eu}^{3+}$ $\left(\lambda_{\mathrm{ex}} \sim 394\right.$ и $\sim 466 \mathrm{~nm}$, электронные переходы ${ }^{7} F_{0} \rightarrow{ }^{5} L_{6}$ и ${ }^{7} F_{0} \rightarrow{ }^{5} D_{2}$ соответственно), в области прозрачности кристалла $(\lambda>300 \mathrm{~nm})[1-3,12,13]$.

Возбуждение свечения редкоземельных ионов светом с энергией, находящейся в области интенсивного поглощения образца $(\lambda=225-300 \mathrm{~nm})$, полоса переноса заряда (ППЗ), позволяет получить информацию о локальном окружении ионов $\mathrm{Eu}^{3+}$ в приповерхностном слое кристалла $[1-3,12,13]$.

В работах [6-8] показано, что если ближний порядок вокруг ионов $\mathrm{Eu}^{3+}$ во всем образце одинаков, о чем свидетельствует совпадение спектров люминесценции (СЛ) приповерхностного слоя образца и его объема, то образец является однофазным.

Ортоборат лютеция имеет две устойчивые структурные модификации: ватерит, который образуется при синтезе $\mathrm{LuBO}_{3}$ при $T=750-850^{\circ} \mathrm{C}$, и кальцит, образую- 
щийся при $T=970-1100^{\circ} \mathrm{C}$. Ион лютеция в структурах кальцита и ватерита окружен, соответственно, шестью и восемью атомами кислорода. Ортобораты $\mathrm{REBO}_{3}$ $(\mathrm{RE}=\mathrm{Eu}, \mathrm{Gd}, \mathrm{Tb}, \mathrm{Dy}, \mathrm{Y})$ и $\mathrm{InBO}_{3}$ имеют разные, но только одну структурную модификацию: ватерит для указанных ортоборатов редкоземельных элементов и кальцит для ортобората индия [16-21]. Твердый раствор $\mathrm{Lu}_{1-x} \mathrm{In}_{x} \mathrm{BO}_{3}$, синтезированный при $780^{\circ} \mathrm{C}$ (температуре существования ватерита $\mathrm{LuBO}_{3}$ ), при $x>0.08-0.1$ кристаллизуется в структуре кальцита [22]. В то же время, твердые растворы $\mathrm{Lu}_{1-x} \mathrm{RE}_{x} \mathrm{BO}_{3}(\mathrm{RE}=\mathrm{Eu}, \mathrm{Gd}$, $\mathrm{Tb}$, Dу и Y) при $x>0.15-0.2$, синтезированные при $T=970-1100^{\circ} \mathrm{C}$ (температурах существования кальцитной фазы $\left.\mathrm{LuBO}_{3}\right)$, кристаллизуются в структуре ватерита $[12,13]$.

Исследования люминесценции соединений $\mathrm{Lu}_{0.98-x} \mathrm{In}_{x} \mathrm{Eu}_{0.02} \mathrm{BO}_{3} \quad$ при возбуждении $\quad$ в полосе переноса заряда $\left(\lambda_{\mathrm{ex}}=250 \mathrm{~nm}\right)$ и при резонансном возбуждении ионов $\mathrm{Eu}^{3+}\left(\lambda_{\mathrm{ex}}=394 \mathrm{~nm}\right)$, показали, что структурные преобразования в ортоборатах $\mathrm{Lu}_{0.98-x} \mathrm{In}_{x} \mathrm{Eu}_{0.02} \mathrm{BO}_{3}$ при увеличении концентрации ионов $\mathrm{In}^{3+}$ начинаются в приповерхностном слое микрокристаллов этих образцов [22]. При $x \geq 0.04$ приповерхностный слой имеет структуру кальцита, при дальнейшем увеличении концентрации индия количество фазы кальцита увеличивается и в объеме образца, а при $x>0.1$ весь образец имеет структуру кальцита.

Исследование синтезированных при $970^{\circ} \mathrm{C}$ ортоборатов $\mathrm{Lu}_{0.99-x} \mathrm{RE}_{x} \mathrm{Eu}_{0.01} \mathrm{BO}_{3} \quad(\mathrm{RE}=\mathrm{Gd}, \mathrm{Eu}, \mathrm{Tb}, \mathrm{Y})$ показало, что с ростом концентрации RE происходят изменения их структуры: при $0 \leq x \leq 0.05-0.1$ твердый раствор ортоборатов является однофазным и имеет структуру кальцита (пр.гр. $R \overline{3} c$ ); при $0.05-0.1<x \leq 0.1-0.25$ наряду со структурой кальцита появляется фаза ватерита (пр.гр. $C 2 / c$ ), а при $x>0.1-0.25$ твердый раствор является однофазным со структурой ватерита (пр. гр. C2/c) $[23,24]$. Одновременно со структурой изменяется и морфология микрокристаллов ортоборатов. Микрокристаллы кальцитной модификации являются крупными с размером частиц $15-20 \mu \mathrm{m}$. В интервале концентраций RE $0.05-0.1<x \leq 0.1-0.25$, в котором образцы являются двухфазными, наряду с крупными появляются мелкие микрокристаллы $(1-2 \mu \mathrm{m})$, количество которых растет при увеличении $x$. При $x>0.1-0.25$ наблюдаются преимущественно микрокристаллы размером $1-2 \mu \mathrm{m}$, имеющие структуру ватерита. Важно отметить, что фаза ватерита появляется в объеме крупных микрокристаллов, имеющих структуру кальцита, и при дальнейшем увеличении концентрации ионов RE - фаза ватерита наблюдается также и на их поверхности.

Таким образом, образование кальцита в микрокристаллах $\mathrm{Lu}_{0.98-x} \mathrm{In}_{x} \mathrm{Eu}_{0.02} \mathrm{BO}_{3}$, имеющих исходную структуру ватерита, при увеличении концентрации $\mathrm{In}^{3+}$ происходит вначале в приповерхностных областях образца, в то время как образование ватерита в исходных крупных микрокристаллах $\mathrm{Lu}_{0.99-x} \mathrm{RE}_{x} \mathrm{Eu}_{0.01} \mathrm{BO}_{3}$, имеющих структуру кальцита, осуществляется при увеличении концентрации $\mathrm{RE}^{3+}$ вначале в объеме этих микрокристаллов.

Важно отметить, что в работах $[12,13,22-24]$ исследовались твердые растворы бората лютеция, имеющего две структурные модификации (ватерит и кальцит) и боратов, имеющих только одну из модификаций бората лютеция: либо кальцит $\left(\mathrm{InBO}_{3}\right)$, либо ватерит $\left(\mathrm{REBO}_{3}\right.$, $\mathrm{RE}=\mathrm{Eu}, \mathrm{Gd}, \mathrm{Tb}, \mathrm{Dy}, \mathrm{Y})$. Представляет интерес изучение структурного состояния твердого раствора $\mathrm{LuBO}_{3}$ и бората, структура которого не является ни кальцитом, ни ватеритом. Этому условию удовлетворяет ортоборат лантана $\left(\mathrm{LaBO}_{3}\right)$, который имеет два фазовых состояния: низкотемпературную орторомбическую фазу арагонит (пр.гр. Рпат) и высокотемпературную моноклинную фазу (пр.гр. $P 2_{1} / m$ ), в которую $\mathrm{LaBO}_{3}$ переходит при температуре $1488^{\circ} \mathrm{C}[17,25]$. В работах $[26,27]$ показано, что температурные последовательности чередования структурных состояний при твердофазном синтезе $\mathrm{LaBO}_{3}$ из аморфных и микрокристаллических прекурсоров различны. При синтезе $\mathrm{LaBO}_{3}$ из микрокристаллического порошка вначале образуется низкотемпературная фаза арагонита (при $900^{\circ} \mathrm{C}$ ), а затем высокотемпературная моноклинная фаза. При синтезе из аморфного прекурсора наблюдается следующая последовательность фаз: (высокотемпературная) моноклинная $\left(T=500^{\circ} \mathrm{C}\right)$, низкотемпературная орторомбическая фаза арагонита $\left(T=800^{\circ} \mathrm{C}\right)$, высокотемпературная моноклинная фаза $\left(T=1488^{\circ} \mathrm{C}\right)$.

Следует отметить, что необычная последовательность чередования структурных состояний наблюдалась ранее при отжиге аморфных образцов молибдата европия $\mathrm{Eu}_{2}\left(\mathrm{MoO}_{4}\right)_{3}$ : аморфное состояние $\rightarrow\left(550^{\circ} \mathrm{C}\right)$ высокотемпературная $\beta$-фаза (метастабильная при этих условиях $) \rightarrow\left(700^{\circ} \mathrm{C}\right) \quad \alpha$-фаза (термодинамически стабильная при этих условиях $) \rightarrow\left(\sim 881^{\circ} \mathrm{C}\right) \beta$-фаза (термодинамически стабильная вплоть до точки плавления) [28]. Исследование свечения при разных длинах волн возбуждения позволило изучить процесс формирования кристаллических фаз на поверхности и в объеме микрокристаллических образцов. При отжиге аморфного $\mathrm{Eu}_{2}\left(\mathrm{MoO}_{4}\right)_{3}$ высокотемпературная $\beta$-фаза зарождается при $500^{\circ} \mathrm{C}$ одновременно и в объеме, и на поверхности микрокристаллов. В то же время, зарождение $\alpha$-фазы, термодинамически стабильной при $T \leq 881^{\circ} \mathrm{C}$, происходит при $\sim 650^{\circ} \mathrm{C}$ в объеме микрокристаллов. При $850^{\circ} \mathrm{C}$ зарождение $\beta$-фазы происходит во всем образце, как в объеме, так и на поверхности микрокристаллов. Такая же последовательность чередования структурных состояний наблюдается при отжиге аморфного $\mathrm{Gd}_{2}\left(\mathrm{MoO}_{4}\right)_{3}(\mathrm{Eu})$ (ионы $\mathrm{Eu}^{3+}$ использовались в качестве структурно-чувствительных и оптически активных меток). Более того, как и в молибдате европия, образование $\beta$-фазы происходит как в объеме, так и на поверхности микрокристаллов (во всем объеме образца), а $\alpha$-фазы - в объеме микрокристаллов [8]. 
Спектры люминесценции (СЛ) и спектры возбуждения люминесценции (СВЛ) ортоборатов $\mathrm{LaBO}_{3}(\mathrm{Eu})$, полученных различными методами и имеющих различную морфологию, исследованы в работах [26,29-31]. В спектрах люминесценции $\mathrm{LaBO}_{3}(\mathrm{Eu})$ наблюдаются полосы, соответствующие переходам ${ }^{5} D_{0} \rightarrow{ }^{7} F_{J}(J=0,1$, $2,3,4)$ в ионах $\mathrm{Eu}^{3+}$. Наибольшую интенсивность имеют полосы с $\lambda_{\max }=588-595 \mathrm{~nm}\left({ }^{5} D_{0} \rightarrow{ }^{7} F_{1}\right)$ и $610-626 \mathrm{~nm}$ $\left({ }^{5} D_{0} \rightarrow{ }^{7} F_{2}\right)$. В спектрах возбуждения люминесценции наибольшую интенсивность имеет коротковолновая полоса переноса заряда (ППЗ) $\lambda_{\mathrm{ex}}=270-285 \mathrm{~nm}$. В длинноволновой области спектра в диапазоне длин волн 300-430 nm в СВЛ наблюдается ряд полос, обусловленных $f \rightarrow f$-переходами в ионе $\mathrm{Eu}^{3+}$. Наибольшую интенсивность имеет полоса с $\lambda_{\mathrm{ex}}=393-394 \mathrm{~nm}\left({ }^{7} F_{0} \rightarrow{ }^{5} L_{6}\right)$.

Структура $\mathrm{LaBO}_{3}$ исследована в работах [27,29,31-34]. Ионы $\mathrm{La}^{3+}$ в структуре арагонита окружены девятью ионами кислорода, а ионы бора имеют тригональную координацию по кислороду. Следует отметить, что в структуре кальцита, например в $\mathrm{LuBO}_{3}$, ионы $\mathrm{Lu}^{3+}$ окружены шестью ионами кислорода, а атомы бора имеют такую же как в арагоните, тригональную координацию по кислороду - $\left(\mathrm{BO}_{3}\right)^{3-}[35]$. В то же время, в структуре ватерита ионы $\mathrm{Lu}^{3+}$ окружены восьмью ионами кислорода, а три атома бора с тетраэдрическим окружением по кислороду образуют группу $\left(\mathrm{B}_{3} \mathrm{O}_{9}\right)^{9-}$ в виде трехмерного кольца $[36,37]$.

В настоящей работе проведены исследования изменений структуры, морфологии, ИК-спектров, а также спектров возбуждения люминесценции и спектров люминесценции твердых растворов $\mathrm{La}_{0.98-x} \mathrm{Lu}_{x} \mathrm{Eu}_{0.02} \mathrm{BO}_{3}$ в широком диапазоне концентраций $\mathrm{Lu}(0 \leq x \leq 0.98)$. Ионы $\mathrm{Eu}^{3+}$ использовались в качестве оптически активных и структурно-чувствительных меток. Установлено соответствие между структурой и спектральными характеристиками этого соединения. Определены составы, имеющие максимальную интенсивность свечения ионов

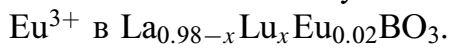

\section{2. Методики эксперимента}

\section{1. Синтез образцов}

Образцы поликристаллических порошков ортоборатов состава $\mathrm{La}_{0.98-x} \mathrm{Lu}_{x} \mathrm{Eu}_{0.02} \mathrm{BO}_{3}$ получали взаимодействием оксидов редкоземельных элементов с расплавом тетрабората калия по реакции

$$
\begin{gathered}
(0.98-x) \mathrm{La}_{2} \mathrm{O}_{3}+x \mathrm{Lu}_{2} \mathrm{O}_{3}+0.02 \mathrm{Eu}_{2} \mathrm{O}_{3}+\mathrm{K}_{2} \mathrm{~B}_{4} \mathrm{O}_{7} \\
=2 \mathrm{La}_{0.98-x} \mathrm{Lu}_{x} \mathrm{Eu}_{0.02} \mathrm{BO}_{3}+\mathrm{K}_{2} \mathrm{~B}_{2} \mathrm{O}_{4} .
\end{gathered}
$$

Взятое в реакцию количество тетрабората калия обеспечивало избыток борсодержащего реагента относительно стехиометрического количества на 10-20\%. Исходными соединениями для синтеза ортоборатов были тетрагидрат тетрабората калия $\mathrm{K}_{2} \mathrm{~B}_{4} \mathrm{O}_{7} \cdot 4 \mathrm{H}_{2} \mathrm{O}$ и оксиды $\mathrm{La}_{2} \mathrm{O}_{3}$,
$\mathrm{Lu}_{2} \mathrm{O}_{3}, \mathrm{Eu}_{2} \mathrm{O}_{3}$. Все использованные химические вещества соответствовали квалификации „ЧДА“.

Синтез микрокристаллических порошков ортоборатов проводился следующим образом. Взвешенные стехиометрические количества оксидов РЗЭ и тетрагидрата тетрабората калия помещали в керамическую чашку, добавляли дистиллированной воды и тщательно перемешивали. Полученную водную суспензию нагревали на плитке и при осторожном кипении отгоняли воду. Полученный твердый продукт отжигали при температуpe $600^{\circ} \mathrm{C}$ в течение 20 min для удаления воды, после чего тщательно перетирали в агатовой ступке. Полученный порошок переносили в керамический тигель и подвергали высокотемпературному отжигу при $T=970^{\circ} \mathrm{C}$ в течение $2 \mathrm{~h}$. Продукт отжига обрабатывали водным раствором соляной кислоты с концентрацией $5 \mathrm{wt} \%$ в течение $0.2 \mathrm{~h}$ при непрерывном перемешивании. Выделение поликристаллов ортоборатов проводили фильтрованием полученной водной суспензии с последующей промывкой водой, спиртом и сушкой продукта на фильтре. Полученные порошки поликристаллов ортоборатов окончательно сушились на воздухе при $T=200^{\circ} \mathrm{C}$ в течение $0.5 \mathrm{~h}$.

\section{2. Методы исследований}

Рентгендифракционные исследования проводили с использованием дифрактометра Rigaku SmartLab SE на $\mathrm{Cu} K_{\alpha}$ излучении, $\lambda=1.54178 \AA, 40 \mathrm{kV}, 35 \mathrm{~mA}$. Угловой интервал $2 \theta=10-140^{\circ}$. Фазовый анализ образцов и расчет параметров решетки проводили с использованием программ Match и PowderCell 2.4.

ИК-спектры образцов измерялись на Фурье-спектрометре VERTEX 80v в спектральном диапазоне $400-5000 \mathrm{~cm}^{-1}$ с разрешением $2 \mathrm{~cm}^{-1}$. Для измерений порошки поликристаллов перетирались в агатовой ступке, а затем тонким слоем наносились на кристаллическую шлифованную подложку $\mathrm{KBr}$.

Морфология образцов изучалась с использованием рентгеновского микроанализатора Supra 50VP с приставкой для EDS INCA (Oxford).

Спектры фотолюминесценции и спектры возбуждения люминесценции изучались на установке, состоящей из источника света - лампы ДКСШ-150, двух монохроматоров МДР-4 и МДР-6 (спектральный диапазон 200-1000 nm, дисперсия $1.3 \mathrm{~nm} / \mathrm{mm}$ ). Регистрация свечения осуществлялась фотоумножителем ФЭУ-106 (область спектральной чувствительности 200-800 nm) и усилительной системой. Монохроматор МДР-4 использовался для изучения спектров возбуждения люминесценции образцов, монохроматор МДР-6 применялся для изучения спектров люминесценции.

Спектральные и структурные характеристики, а также морфология образцов, исследовались при комнатной температуре. 


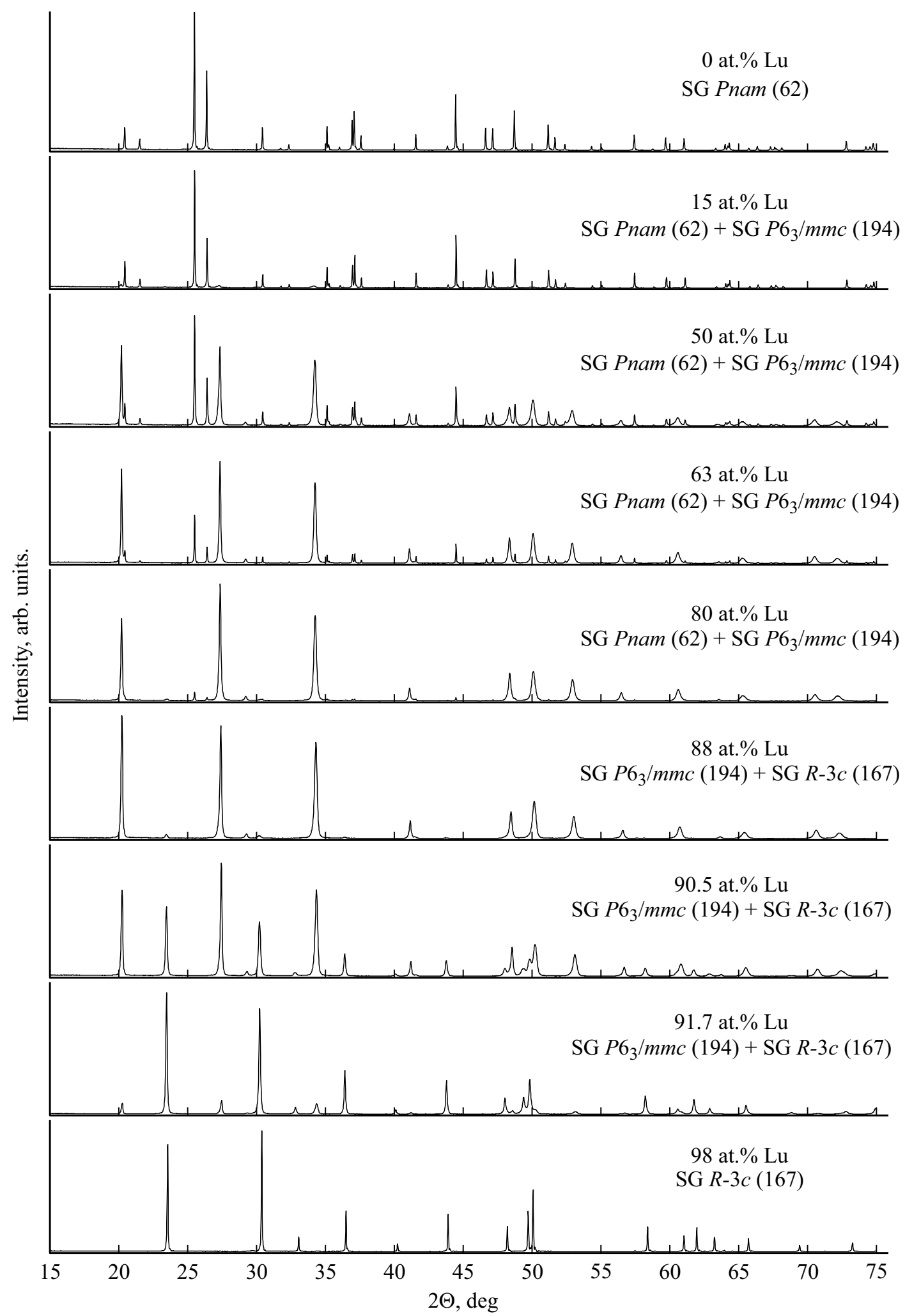

Рис. 1. Дифрактограммы образцов $\mathrm{La}_{0.98-x} \mathrm{Lu}_{x} \mathrm{Eu}_{0.02} \mathrm{BO}_{3}(0 \leq x \leq 0.98)$.

\section{3. Рентгеноструктурные исследования}

Дифрактограммы порошковых образцов исследуемых соединений $\mathrm{La}_{0.98-x} \mathrm{Lu}_{x} \mathrm{Eu}_{0.02} \mathrm{BO}_{3}$ и их фазовый состав при $0 \leq x \leq 0.98$ представлены на рис. 1 и 2. При увеличении концентрации $\mathrm{Lu}^{3+}$ происходит последовательная смена различных типов структурных модификаций. При $0 \leq x<0.15$ образцы являются однофазными и имеют 
Таблица 1. Влияние концентрации $\mathrm{Lu}^{3+}$ на содержание фаз арагонита, ватерита и кальцита в ортоборатах $\mathrm{La}_{0.98-x} \mathrm{Lu}_{x} \mathrm{Eu}_{0.02} \mathrm{BO}_{3}$

\begin{tabular}{|c|c|c|c|c|c|c|}
\hline $\begin{array}{c}\text { Концентрация } \\
\mathrm{La}^{3+} \text {, at.\% }\end{array}$ & $\begin{array}{c}\text { Арагонит } \\
\text { (PDF 12-0762), } \\
\%\end{array}$ & $\begin{array}{c}\text { Объем элементарной } \\
\text { ячейки арагонита, } \\
\text { приведенный } \\
\text { к } Z=2, \AA^{3}\end{array}$ & $\begin{array}{c}\text { Ватерит SG } 194 \\
\text { (PDF 74-1938), } \\
\%\end{array}$ & $\begin{array}{c}\text { Объем } \\
\text { элементарной } \\
\text { ячейки ватерита, } \\
Z=2, \AA^{3}\end{array}$ & $\begin{array}{c}\text { Кальцит SG } 167 \\
\text { (PDF-72-1053), } \\
\%\end{array}$ & $\begin{array}{c}\text { Объем элементарной } \\
\text { ячейки кальцита, } \\
\text { приведенный } \\
\text { к } Z=2, \AA^{3}\end{array}$ \\
\hline 0 & 100 & 123.6 & 0 & & 0 & \\
\hline 5 & 100 & 123.4 & 0 & & 0 & \\
\hline 10 & 100 & 123.3 & 0 & & 0 & \\
\hline 15 & 97 & 123.3 & 3 & & 0 & \\
\hline 20 & 89 & 123.3 & 11 & & 0 & \\
\hline 30 & 73 & 123.4 & 27 & 107.9 & 0 & \\
\hline 50 & 55 & 123.3 & 45 & 107.7 & 0 & \\
\hline 63 & 29 & 123.3 & 71 & 107.6 & 0 & \\
\hline 73 & 20 & 123.1 & 80 & 107.6 & 0 & \\
\hline 80 & 4 & & 96 & 107.5 & 0 & \\
\hline 88 & 0 & & 98 & 107.1 & 2 & \\
\hline 90.5 & 0 & & 64 & 106.0 & 36 & 114.1 \\
\hline 91.7 & 0 & & 13 & 106.1 & 87 & 114.3 \\
\hline 93 & 0 & & 0 & & 100 & 114.4 \\
\hline 98 & 0 & & 0 & & 100 & 113.2 \\
\hline 1) 90 & 0 & & 93 & & 7 & \\
\hline
\end{tabular}

Примечание. ${ }^{1)}$ Образец $\mathrm{La}_{0.1} \mathrm{Lu}_{0.9} \mathrm{BO}_{3}$

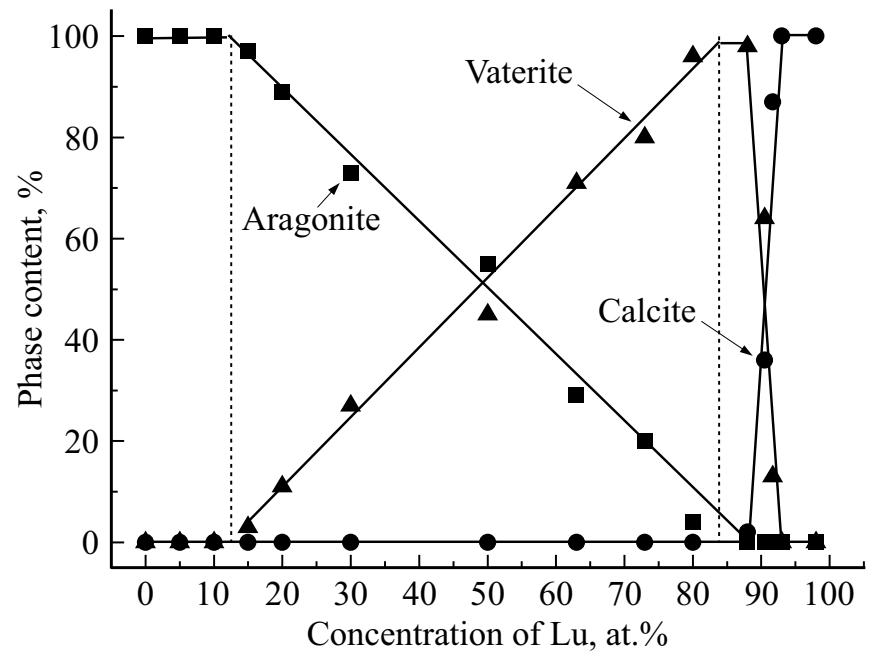

Рис. 2. Фазовый состав синтезированных образцов $\mathrm{La}_{0.98-x} \mathrm{Lu}_{x} \mathrm{Eu}_{0.02} \mathrm{BO}_{3}$ в зависимости от соотношения редких земель в шихте при $0 \leq x \leq 0.98:$ квадрат - арагонит, треугольник - ватерит, круг — кальцит.

структуру арагонита, пр. гр. Pnam № 62 (PDF 12-0762), $Z=4$. В интервале $0.15 \leq x \leq 0.80$ образцы являются двухфазными - наряду со структурой арагонита наблюдается фаза ватерита, пр.гр. $P 6_{3} / m m c$ № 194 (PDF 74-1938), $Z=2$. При $0.88 \leq x \leq 0.98$ фаза арагонита в образцах не наблюдается. В ортоборате состава $\mathrm{La}_{0.10} \mathrm{Lu}_{0.88} \mathrm{Eu}_{0.02} \mathrm{BO}_{3}$ наряду с ватеритом появляется фаза кальцита, пр.гр. $R \overline{3} c$ № 167 (PDF 72-1053), $Z=6$, количество которой увеличивается с ростом концентрации $\mathrm{Lu}^{3+}$. При $0.88 \leq x<0.93$ образцы являются двухфазными - они содержат фазы ватерита и кальцита. В интервале концентраций $0.93 \leq x \leq 0.98$ образцы однофазные со структурой кальцита.

При концентрациях лютеция $0 \leq x<0.15$ в однофазном образце со структурой арагонита наблюдается монотонное уменьшение объема элементарной ячейки при увеличении $x$, что свидетельствует о растворении лютеция в структуре арагонита. При $x \geq 0.15$ в образце, наряду с арагонитом появляется вторая фаза - ватерит, при появлении которой объем элементарной ячейки

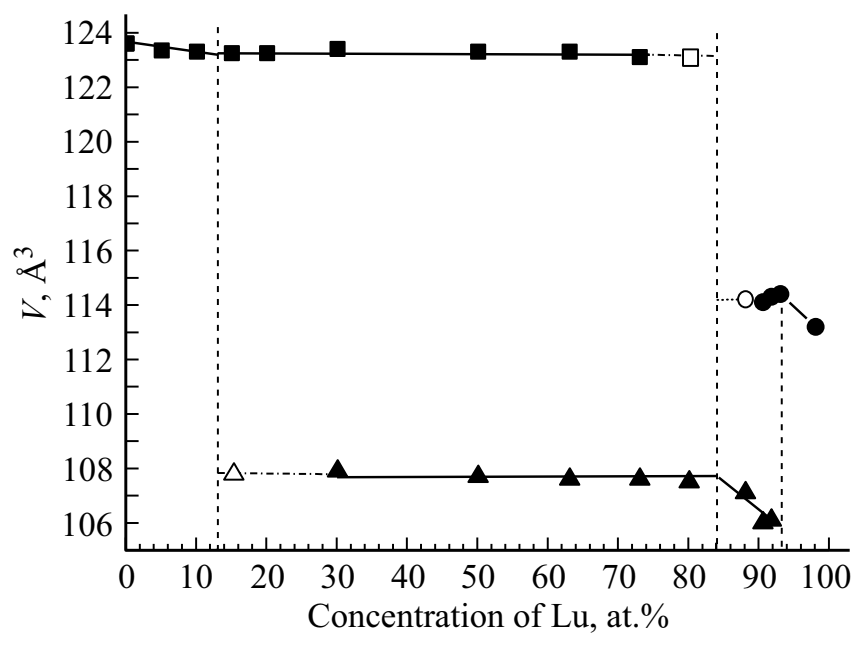

Рис. 3. Объемы элементарных ячеек структурных модификаций $\mathrm{La}_{0.98-x} \mathrm{Lu}_{x} \mathrm{Eu}_{0.02} \mathrm{BO}_{3}$ при $0 \leq x \leq 0.98$, приведенные к $Z=2$ : квадрат - арагонит, треугольник - ватерит, круг кальцит (предполагаемые значения объемов: пустой квадрат арагонит, пустой треугольник - ватерит, пустой круг кальцит). 


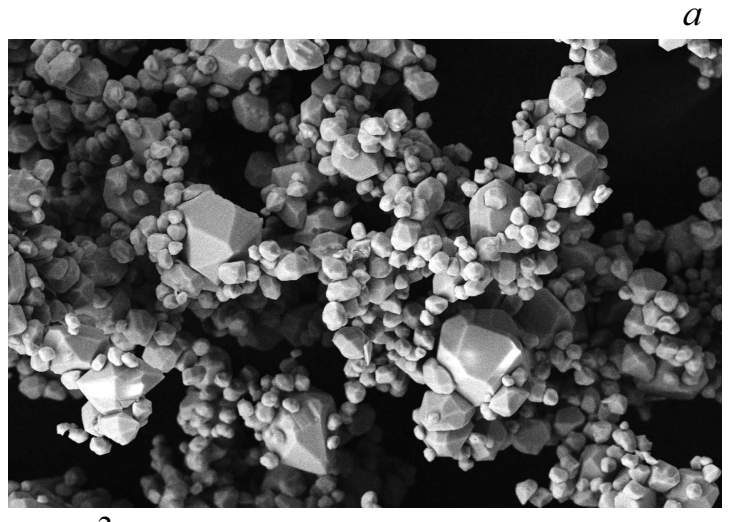

$$
-3 \mu \mathrm{m}
$$

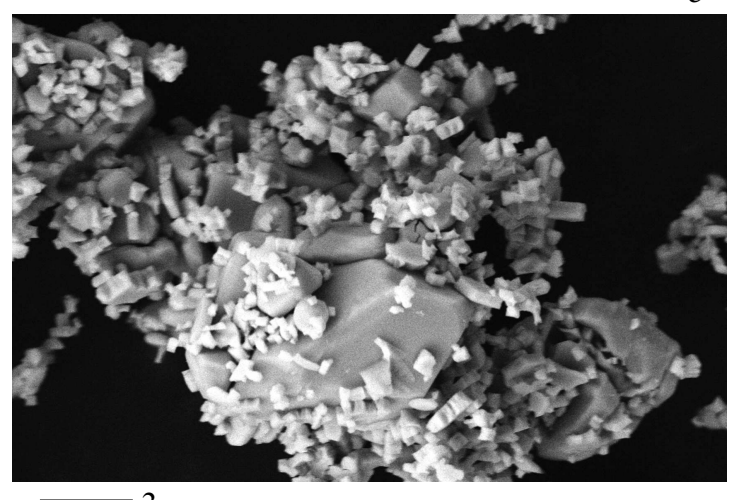

$-3 \mu \mathrm{m}$
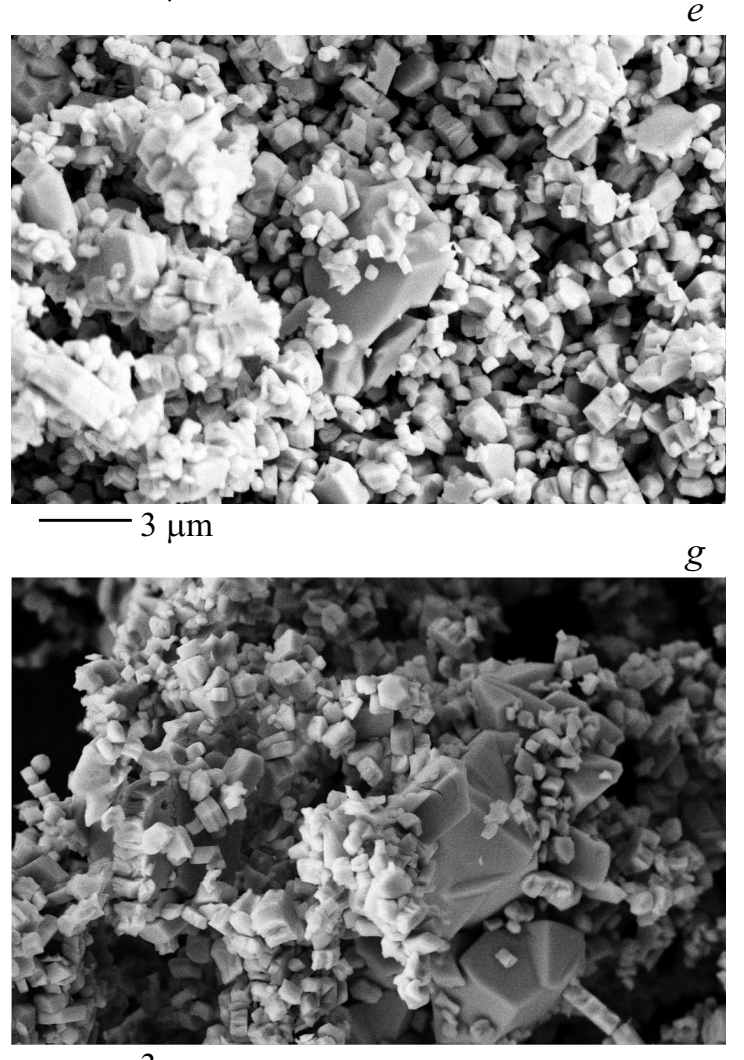

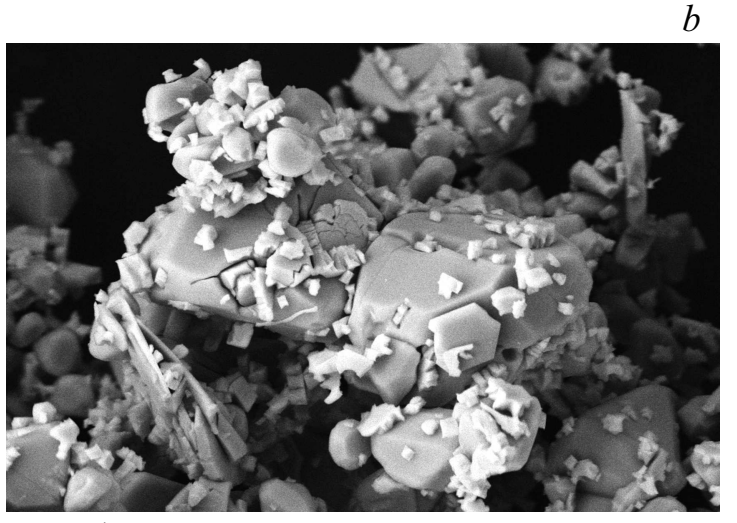

$-1 \mu \mathrm{m}$
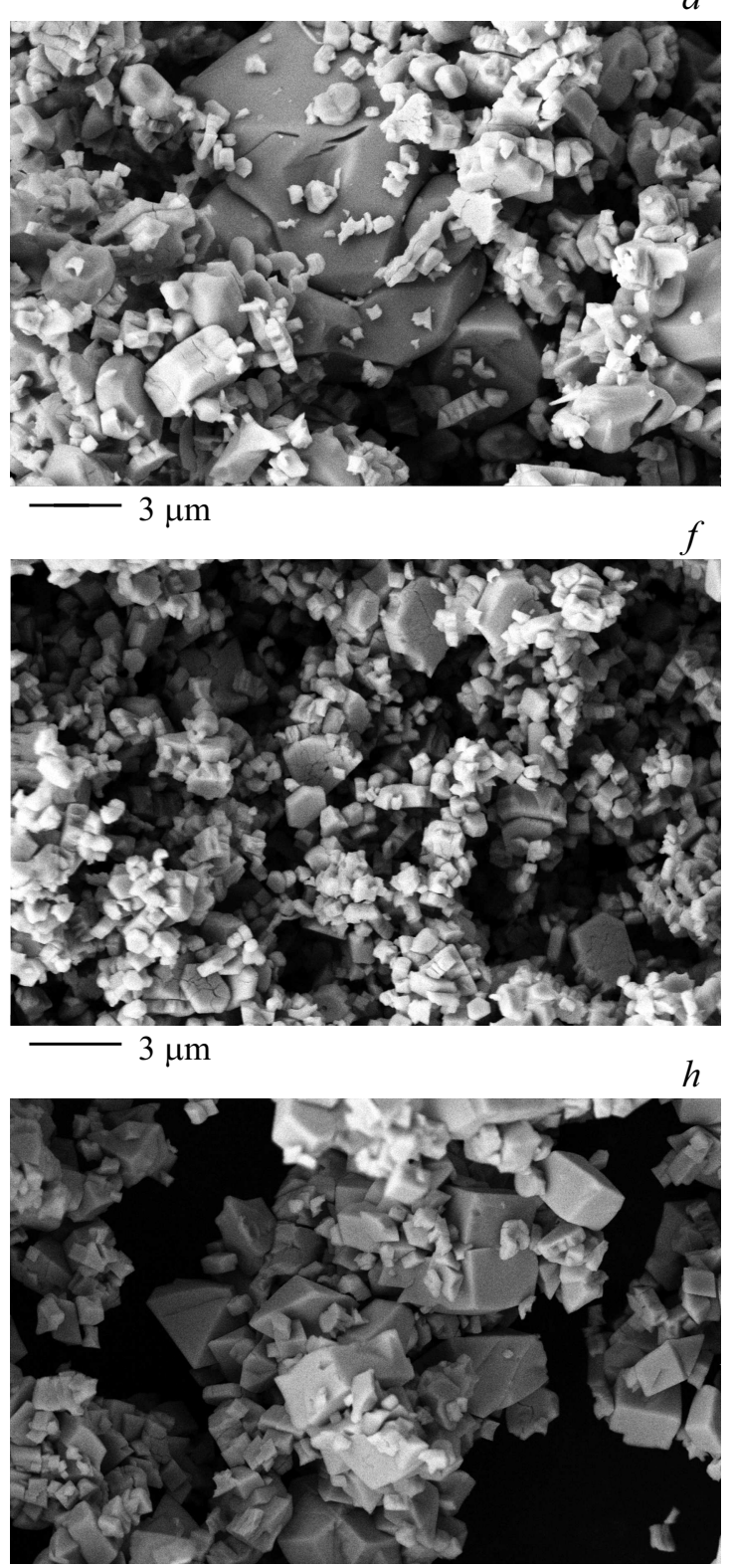

$-3 \mu \mathrm{m}$

Рис. 4. Морфология образцов $\mathrm{La}_{0.98-x} \mathrm{Lu}_{x} \mathrm{Eu}_{0.02} \mathrm{BO}_{3} . a-\mathrm{La}_{0.98} \mathrm{Eu}_{0.02} \mathrm{BO}_{3} ; b-\mathrm{La}_{0.78} \mathrm{Lu}_{0.2} \mathrm{Eu}_{0.02} \mathrm{BO}_{3} ; c-\mathrm{La}_{0.68} \mathrm{Lu}_{0.3} \mathrm{Eu}_{0.02} \mathrm{BO}_{3} ; d-$ $\mathrm{La}_{0.48} \mathrm{Lu}_{0.5} \mathrm{Eu}_{0.02} \mathrm{BO}_{3} ; e-\mathrm{La}_{0.25} \mathrm{Lu}_{0.73} \mathrm{Eu}_{0.02} \mathrm{BO}_{3} ; f-\mathrm{La}_{0.1} \mathrm{Lu}_{0.88} \mathrm{Eu}_{0.02} \mathrm{BO}_{3} ; g-\mathrm{La}_{0.075} \mathrm{Lu}_{0.905} \mathrm{Eu}_{0.02} \mathrm{BO}_{3} ; h-\mathrm{La}_{0.063} \mathrm{Lu}_{0.917} \mathrm{Eu}_{0.02} \mathrm{BO}_{3} ;$ $k-\mathrm{La}_{0.05} \mathrm{Lu}_{0.93} \mathrm{Eu}_{0.02} \mathrm{BO}_{3} ; l-\mathrm{Lu}_{0.98} \mathrm{Eu}_{0.02} \mathrm{BO}_{3}$. 
$k$
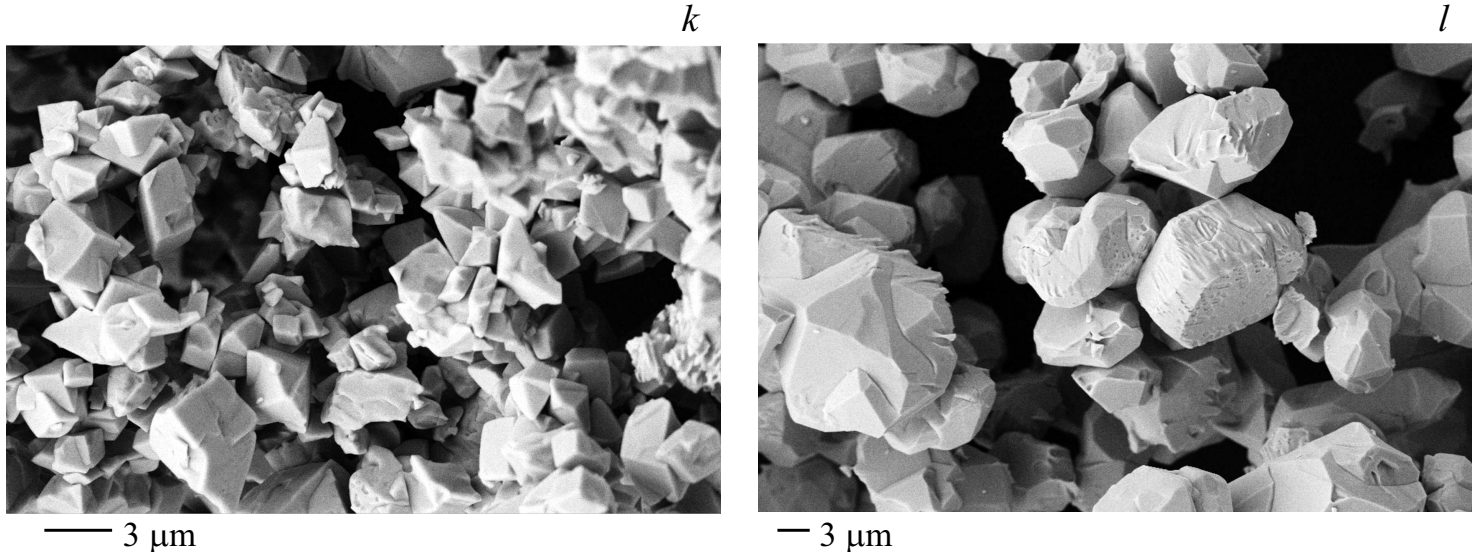

Рис. 4 (продолжение).

арагонита остается постоянным. Избыточный лютеций уже не входит в структуру арагонита, а расходуется на рост количества ватеритной фазы.

В двухфазной области $0.15 \leq x \leq 0.80$ (арагонит + ватерит) объем элементарной ячейки ватерита также не изменяется, что свидетельствует о постоянстве состава и в ватеритной структуре. Примерный состав ватеритной фазы, определенный по границе изменения объема элементарной ячейки ватерита, $\sim \mathrm{La}_{0.14} \mathrm{Lu}_{0.84} \mathrm{Eu}_{0.02} \mathrm{BO}_{3}$. Как видно из рис. 3 , в интервале концентраций $\mathrm{Lu}^{3+} 0.15 \leq x \leq 0.80$ изменяется соотношение фаз арагонита и ватерита.

Для образцов, имеющих структуру кальцита, при $0.93 \leq x \leq 0.98$, объем элементарной ячейки уменьшается при увеличении концентрации $\mathrm{Lu}^{3+}$. Следовательно, при легировании $\mathrm{Lu}_{0.98} \mathrm{Eu}_{0.02} \mathrm{BO}_{3}$ ионами $\mathrm{La}^{3+}$ в диапазоне концентраций 0-5 at.\% происходит увеличение объема элементарной ячейки кальцита, что свидетельствует о растворении лантана в ортоборате лютеция, имеющего структуру кальцита. В двухфазной области (при $0.88 \leq x<0.93$ ) объем элементарной ячейки кальцита постоянен, объем элементарной ячейки ватерита растет с увеличением концентрации лантана в шихте (то есть уменьшается с ростом содержания лютеция), изменяется и соотношение между количеством фаз ватерита и кальцита (табл. 1, рис. 3)

Таким образом, на основании рентгеноструктурных исследований соединений $\mathrm{La}_{0.98-x} \mathrm{Lu}_{x} \mathrm{Eu}_{0.02} \mathrm{BO}_{3}$ можно сделать следующие выводы.

При $0 \leq x<0.15$ образцы являются однофазными и имеют структуру арагонита; при $0.15 \leq x \leq 0.8$ образцы являются двухфазными - они содержат фазы арагонита и ватерита; при $0.8<x<0.88$ доминирующей фазой является ватерит; при $0.88 \leq x<0.93$ образцы являются двухфазными и содержат фазы ватерита и кальцита; при $0.93 \leq x \leq 0.98$ образцы имеют структуру кальцита.

Максимально возможное растворение ионов $\mathrm{Lu}^{3+}$ в фазе арагонита $\mathrm{La}_{0.98} \mathrm{Eu}_{0.02} \mathrm{BO}_{3}$ составляет $\sim 13$ ат.\%.
Состав образующегося твердого раствора $\sim \mathrm{La}_{0.85} \mathrm{Lu}_{0.13} \mathrm{Eu}_{0.02} \mathrm{BO}_{3}$.

Максимально возможное растворение ионов $\mathrm{La}^{3+}$ в фазе кальцита $\mathrm{Lu}_{0.98} \mathrm{Eu}_{0.02} \mathrm{BO}_{3}$ составляет всего лишь $\sim 5$ ат.\%. Состав образующегося твердого раствора $\sim \mathrm{La}_{0.05} \mathrm{Lu}_{0.93} \mathrm{Eu}_{0.02} \mathrm{BO}_{3}$. Такое низкое значение величины предельной растворимости $\mathrm{La}^{3+}$ в фазе кальцита $\mathrm{Lu}_{0.98} \mathrm{Eu}_{0.02} \mathrm{BO}_{3}$ обусловлено, по-видимому, большой разницей величин ионных радиусов $\mathrm{La}^{3+}(1.115 \AA)$ и $\mathrm{Lu}^{3+}(0.848 \AA)[38]$.

\section{4. Морфология образцов}

В образцах $\mathrm{La}_{0.98-x} \mathrm{Lu}_{x} \mathrm{Eu}_{0.02} \mathrm{BO}_{3}$ в диапазоне концентраций $\mathrm{Lu}^{3+} 0 \leq x \leq 0.1$, имеющих согласно данным рентгенофазового анализа структуру арагонита (табл. 1), наблюдаются мелкие (размером 1-2 $\mu \mathrm{m}$ ) и крупные $(\sim 6-12 \mu \mathrm{m})$ микрокристаллы (рис. 4,a). При $0.3 \leq x \leq 0.8$ размеры мелких кристаллов уменьшаются до $0.3-0.5 \mu \mathrm{m}$, а крупных до 3-6 $\mu \mathrm{m}$. Увеличение концентрации ионов $\mathrm{Lu}^{3+}$ приводит к уменьшению количества арагонита и увеличению количества ватерита (табл. 1). С ростом количества ватерита увеличивается количество мелких кристаллов $(0.3-0.5 \mu \mathrm{m})$ (рис. 4, $b, c, d, e)$ Образцы $\mathrm{La}_{0.1} \mathrm{Lu}_{0.88} \mathrm{Eu}_{0.02} \mathrm{BO}_{3}$, содержащие 98\% ватерита и 2\% кальцита (табл. 1), состоят из микрокристаллов размером 0.3-0.5 и $\sim 2 \mu \mathrm{m}$ (рис. 4,f). При $0.88<x<0.93$ количество мелких микрокристаллов $(0.3-0.5 \mu \mathrm{m})$ уменьшается, а количество микрокристаллов размером 2-5 $\mu \mathrm{m}$ увеличивается (рис. $3, g, h$ ). В этом диапазоне концентраций ионов $\mathrm{Lu}^{3+}$ наблюдается уменьшение количества фазы ватерита и увеличение доли фазы кальцита (табл. 1). В образцах $\mathrm{La}_{0.05} \mathrm{Lu}_{0.93} \mathrm{Eu}_{0.02} \mathrm{BO}_{3}$, содержащих $100 \%$ кальцита наблюдаются только микрокристаллы размером $3-5 \mu \mathrm{m}$ (рис. 4, $k$ ). Ортобораты $\mathrm{Lu}_{0.98} \mathrm{Eu}_{0.02} \mathrm{BO}_{3}$, не содержащие ионов $\mathrm{La}^{3+}$, имеющие также структуру кальцита (табл. 1) состоят из микрокристаллов размером $10-15 \mu \mathrm{m}$ (рис. $4, l$ ). Таким образом, добавление 
в $\mathrm{Lu}_{0.98} \mathrm{Eu}_{0.02} \mathrm{BO}_{3}$ небольшого количества ионов $\mathrm{La}^{3+}$ (5at.\%) приводит к заметному изменению размеров микрокристаллов, но не изменяет структуру образца (табл. 1).

На основании исследования морфологии $\mathrm{La}_{0.98-x} \mathrm{Lu}_{x} \mathrm{Eu}_{0.02} \mathrm{BO}_{3}$ при $0 \leq x \leq 0.98$ можно сделать следующие выводы. При использованном в настоящей работе способе синтеза образцы, имеющие структуру арагонита, состоят из мелких $(\sim 1-2 \mu \mathrm{m})$ и крупных $(\sim 6-12 \mu \mathrm{m})$ микрокристаллов (рис. 4,a). Ортобораты $\mathrm{La}_{0.1} \mathrm{Lu}_{0.88} \mathrm{Eu}_{0.02} \mathrm{BO}_{3} \quad(98 \%$ ватерита, $2 \%$ кальцита $)$ состоят из мелких микрокристаллов размером 0.3-0.5 и $\sim 2 \mu \mathrm{m}$ (рис. 4,f), в то время как полученные таким же методом и имеющие структуру ватерита соединения $\mathrm{Lu}_{1-x} \mathrm{RE}_{x} \mathrm{BO}_{3} \quad(\mathrm{RE}=\mathrm{Eu}, \mathrm{Gd}, \mathrm{Tb})$ состоят из микрокристаллов размером $(\sim 1-2 \mu \mathrm{m})$ [23,24]. Соединения $\mathrm{La}_{0.98-x} \mathrm{Lu}_{x} \mathrm{Eu}_{0.02} \mathrm{BO}_{3} \quad(0.93 \leq x \leq 0.98)$, имеющие структуру кальцита, состоят из микрокристаллов, размеры которых при $x=0.93$ и 0.98 равны $3-5$ и $10-15 \mu \mathrm{m}$ соответственно (рис. $4, k, l$ ).

\section{5. Результаты ИК-спектроскопии}

На рис. 5 приведены ИК-спектры соединений $\mathrm{La}_{0.98-x} \mathrm{Lu}_{x} \mathrm{Eu}_{0.02} \mathrm{BO}_{3}$ при $0 \leq x \leq 0.98$ в частотном диапазоне колебаний связей $\mathrm{B}-\mathrm{O}$. В спектре образца состава $\mathrm{La}_{0.98} \mathrm{Eu}_{0.02} \mathrm{BO}_{3}$ (рис. 5, спектр 1) наблюдаются полосы поглощения 592, 612, 721, 789, 939 и $1302 \mathrm{~cm}^{-1}$. Рентгенофазовый анализ показал, что это соединение имеет структуру низкотемпературного арагонита $\mathrm{LaBO}_{3}$ (рис. 1, табл. 1), кристаллическая структура которого содержит плоские тригональные группы $\mathrm{BO}_{3}$ [32].

Из анализа колебаний планарных ионов $\left(\mathrm{BO}_{3}\right)^{3-}$ в соединениях со структурой арагонита следует, что в ИК-спектрах этих образцов должно наблюдаться 6 полос поглощения, связанных с колебаниями связей В-О. Две полосы $v_{3}$ и одна полоса $v_{1}$ - валентные асимметричные и симметричные колебания соответственно, две полосы $v_{4}$ и одна $v_{2}$ - деформационные внутриплоскостные и внеплоскостные колебания соответственно [35]. В спектрах образцов $\mathrm{LaBO}_{3}$ расщепление полосы колебаний $v_{3}$ не наблюдается, а дублет полосы $v_{2}$ объясняется присутствием в образцах $2-\mathrm{x}$ изотопов бора $-\mathrm{B}^{10}$ и $\mathrm{B}^{11}[35,39]$. Полосы ИК-поглощения 592 и $612 \mathrm{~cm}^{-1}$ относятся к колебанию $v_{4}$, дублет 721,789 и полоса поглощения $939 \mathrm{~cm}^{-1}-$ к $v_{2}$ и $v_{1}$ соответственно, а полоса $1302 \mathrm{~cm}^{-1}$ - к колебанию $v_{3}$ (рис. 5, спектр 1). Подобные ИК-спектры образцов со структурой арагонита наблюдались в работах [35,39-41].

ИК-спектр образца $\mathrm{La}_{0.88} \mathrm{Lu}_{0.1} \mathrm{Eu}_{0.02} \mathrm{BO}_{3}$ (рис. 5, спектр 2), который имеет орторомбическую структуру арагонита (табл. 1), совпадает со спектром $\mathrm{La}_{0.98-x} \mathrm{Eu}_{0.02} \mathrm{BO}_{3}$ (рис. 5, спектр 1). При дальнейшем увеличении концентрации $\mathrm{Lu}$ в спектрах образцов $\mathrm{La}_{0.98-x} \mathrm{Lu}_{x} \mathrm{Eu}_{0.02} \mathrm{BO}_{3}$ при $0.15<x \leq 0.88$ наряду с

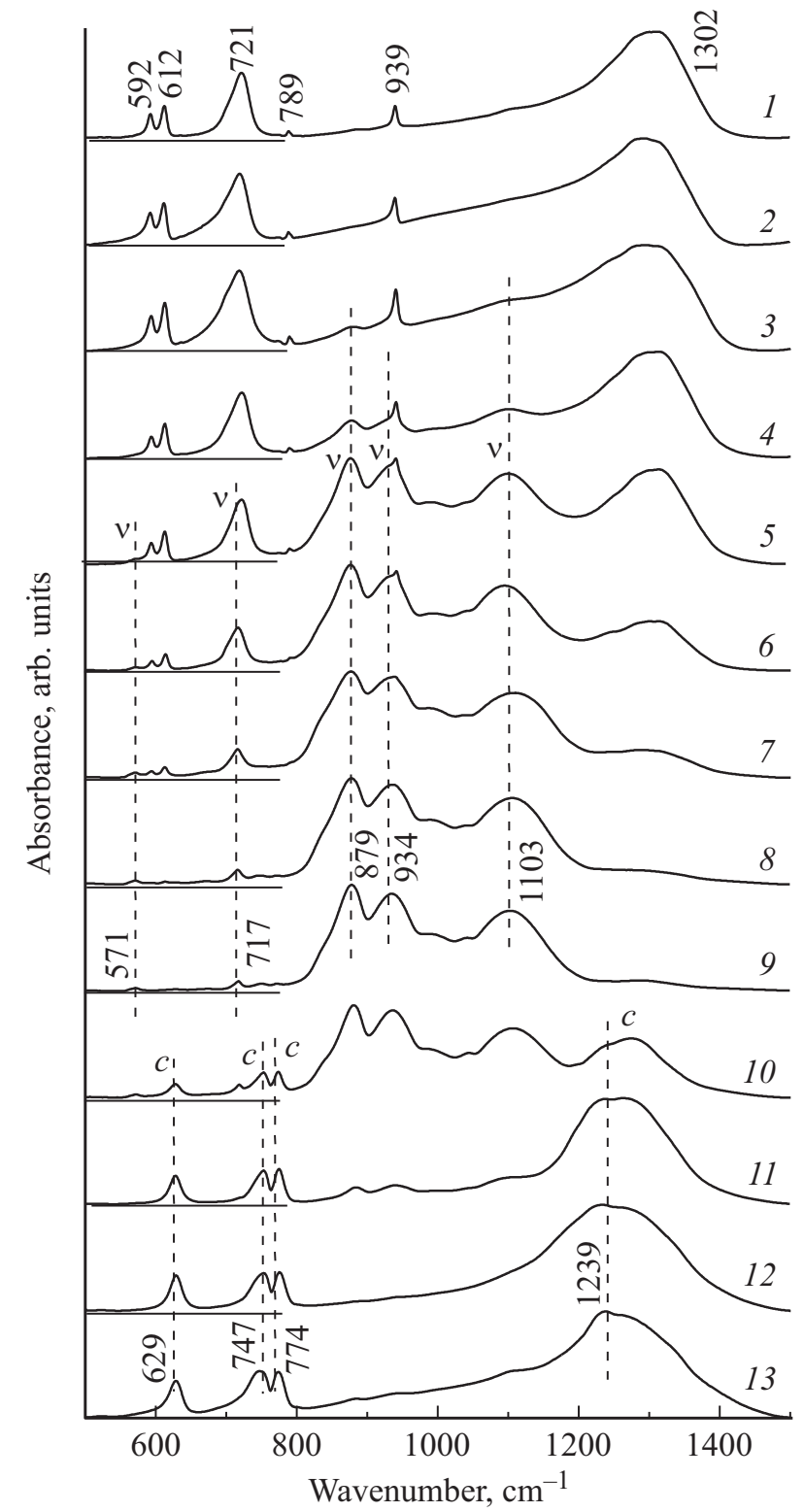

Рис. 5. ИК-спектры ортоборатов $\mathrm{La}_{0.98-x} \mathrm{Lu}_{x} \mathrm{Eu}_{0.02} \mathrm{BO}_{3}$. $1-\mathrm{La}_{0.98} \mathrm{Eu}_{0.02} \mathrm{BO}_{3} ; 2-\mathrm{La}_{0.88} \mathrm{Lu}_{0.1} \mathrm{Eu}_{0.02} \mathrm{BO}_{3} ; 3-$ $\mathrm{La}_{0.83} \mathrm{Lu}_{0.15} \mathrm{Eu}_{0.02} \mathrm{BO}_{3} ; 4-\mathrm{La}_{0.78} \mathrm{Lu}_{0.2} \mathrm{Eu}_{0.02} \mathrm{BO}_{3} ; 5-$ $\mathrm{La}_{0.68} \mathrm{Lu}_{0.3} \mathrm{Eu}_{0.02} \mathrm{BO}_{3} ; \quad 6-\mathrm{La}_{0.48} \mathrm{Lu}_{0.5} \mathrm{Eu}_{0.02} \mathrm{BO}_{3} ; \quad 7 \quad$ $\mathrm{La}_{0.35} \mathrm{Lu}_{0.63} \mathrm{Eu}_{0.02} \mathrm{BO}_{3} ; 8-\mathrm{La}_{0.18} \mathrm{Lu}_{0.8} \mathrm{Eu}_{0.02} \mathrm{BO}_{3} ; 9-$ $\mathrm{La}_{0.10} \mathrm{Lu}_{0.88} \mathrm{Eu}_{0.02} \mathrm{BO}_{3} ; 10-\mathrm{La}_{0.075} \mathrm{Lu}_{0.905} \mathrm{Eu}_{0.02} \mathrm{BO}_{3} ; 11-$ $\mathrm{La}_{0.063} \mathrm{Lu}_{0.917} \mathrm{Eu}_{0.02} \mathrm{BO}_{3} ; 12-\mathrm{La}_{0.05} \mathrm{Lu}_{0.93} \mathrm{Eu}_{0.02} \mathrm{BO}_{3} ; 13-$ $\mathrm{Lu}_{0.98} \mathrm{Eu}_{0.02} \mathrm{BO}_{3}$. Для спектров 1-12 нулевые значения осей ординат показаны тонкой сплошной линией.

полосами поглощения арагонита, появляются дополнительные полосы („v“, вертикальный пунктир) (рис. 5, спектры 3-9). Их интенсивность растет с увеличением концентрации $\mathrm{Lu}$, в то время как интенсивность полос фазы арагонита падает. Поскольку легирующим элементом является $\mathrm{Lu}$, то в условиях проводимого синтеза возможно образование ортобората $\mathrm{LuBO}_{3}$. Ортоборат лютеция имеет две устойчивые структурные 
модификации: ватерит и кальцит. В фазе кальцита ионы бора имеют тригональную координацию по кислороду $\left(\mathrm{BO}_{3}\right)^{3-}[35]$. В структуре ватерита три бор-кислородных тетраэдра образуют группу $\left(\mathrm{B}_{3} \mathrm{O}_{9}\right)^{9-}$ в виде трехмерного кольца [35,37].

Различное окружение атомов бора проявляется в ИК-спектрах: полоса поглощения валентных колебаний $\mathrm{B}-\mathrm{O}-$ связей в структуре ватерита находится в диапазоне $800-1200 \mathrm{~cm}^{-1}$, а в структуре кальцита ее максимум расположен вблизи $1300 \mathrm{~cm}^{-1}[35,42,43]$. Самые интенсивные дополнительные полосы, наблюдаемые в ИК-спектрах (рис. 5, спектры 3-9), лежат в диапазоне 800-1200 $\mathrm{cm}^{-1}$. Согласно данным рентгенофазового анализа образцы $\mathrm{La}_{0.98-x} \mathrm{Lu}_{x} \mathrm{Eu}_{0.02} \mathrm{BO}_{3}$ при $0.15<x \leq 0.8$ действительно содержат фазы арагонита и ватерита (табл. 1). В спектрах образцов $\mathrm{La}_{0.18} \mathrm{Lu}_{0.8} \mathrm{Eu}_{0.02} \mathrm{BO}_{3}$ и $\mathrm{La}_{0.1} \mathrm{Lu}_{0.88} \mathrm{Eu}_{0.02} \mathrm{BO}_{3}$ (рис. 5, спектры 8,9), в которых доминирующей фазой является ватерит, наблюдаются линии 571, 717, 879, 934 и $1103 \mathrm{~cm}^{-1}$. По результатам рентгенофазового анализа ватерит имеет гексагональную структуру (пр. гр. $P 6_{3} / m m c$ № 194). В ИК-спектрах $\mathrm{LuBO}_{3}(\mathrm{~Tb})$ со структурой ватерита гексагональной симметрии $P 6_{3} / m m c[44,45]$ в диапазоне частот 800-1200 $\mathrm{cm}^{-1}$ наблюдались три интенсивные полосы, обусловленные валентными колебаниями В-Освязей кольца и терминальной связи В-О. В исследуемых в настоящей работе образцах также наблюдаются 3 интенсивные полосы 879, 934 и $1103 \mathrm{~cm}^{-1}$ (рис. 5, спектры 8,9).

При увеличении концентрации $\mathrm{Lu}^{3+}(0.88 \leq x<0.93)$ в ИК-спектрах соединений $\mathrm{La}_{0.98-x} \mathrm{Lu}_{x} \mathrm{Eu}_{0.02} \mathrm{BO}_{3}$ наряду с полосами поглощения ватерита появляются дополнительные полосы („сс“, вертикальный пунктир), характерные для структуры кальцита $\mathrm{LuBO}_{3}[13,35]$. При увеличении $x$ интенсивности полос, соответствующих структуре ватерита, уменьшаются, а полос „с“ - увеличиваются (рис. 5, спектры 9-11). Эти результаты находятся в соответствии с данными рентгенофазового анализа, согласно которым соотношения фаз ватерит/кальцит образцов, в составе которых находится 88, 90.5 и 91.7 at.\% ионов $\mathrm{Lu}^{3+}$, составляют 98/2, 64/36 и 13/87\% соответственно (табл. 1 ).

ИК-спектры образцов $\quad \mathrm{La}_{0.05} \mathrm{Lu}_{0.93} \mathrm{Eu}_{0.02} \mathrm{BO}_{3} \quad$ и $\mathrm{Lu}_{0.98} \mathrm{Eu}_{0.02} \mathrm{BO}_{3}$, которые имеют структуру кальцита (табл. 1), являются типичными спектрами фазы кальцита (рис. 5, спектры 12,13). Структура кальцита, так же как и структура арагонита, содержит плоские тригональные $\mathrm{BO}_{3}$-группы. Полосы поглощения 629 и 747, 774 обусловлены внутриплоскостными и внеплоскостными деформационными колебаниям связей $\mathrm{B}-\mathrm{O}-v_{4}$ и $v_{2}$, соответственно, а полоса с максимумом $\sim 1239 \mathrm{~cm}^{-1}-$ их валентными асимметричными колебаниями $v_{3}[13,35]$.

Таким образом, эволюция ИК-спектров в спектральной области колебаний $\mathrm{B}-\mathrm{O}-$ связей показала, что $\mathrm{c}$ ростом концентрации лютеция в образцах $\mathrm{La}_{0.98-x} \mathrm{Lu}_{x} \mathrm{Eu}_{0.02} \mathrm{BO}_{3}$ переход от структуры арагонита, где бор имеет тригональную координацию, к структуре кальцита, также имеющего тригональную координацию бора, происходит через образование фазы ватерита, имеющей тетраэдрическую координацию бора. Эти результаты согласуются с данными рентгеноструктурного анализа (табл. 1 , рис. 2).

\section{6. Спектры люминесценции и спектры возбуждения люминесценции}

Согласно данным рентгенофазового анализа (раздел 3) в ортоборатах $\mathrm{La}_{0.98-x} \mathrm{Lu}_{x} \mathrm{Eu}_{0.02} \mathrm{BO}_{3}$ при увеличении $x$ наблюдается последовательная смена различных типов кристаллических фаз: арагонита; арагонита и ватерита; ватерита; ватерита и кальцита; кальцита. Спектры возбуждения люминесценции основных полос свечения и спектры люминесценции соединений $\mathrm{La}_{0.98-x} \mathrm{Lu}_{x} \mathrm{Eu}_{0.02} \mathrm{BO}_{3}$ при $0 \leq x \leq 0.98$ представлены на рис. 6 и 7.

\section{1. Спектры возбуждения люминесценции}

Спектр возбуждения наиболее интенсивной полосы свечения ортобората $\mathrm{La}_{0.98} \mathrm{Eu}_{0.02} \mathrm{BO}_{3}$ представлен на рис. 6, спектр 1. Аналогичные спектры наблюдаются для образцов $\mathrm{La}_{0.98-x} \mathrm{Lu}_{x} \mathrm{Eu}_{0.02} \mathrm{BO}_{3}$ при $0 \leq x \leq 0.3$. В спектре возбуждения наиболее интенсивной полосы свечения ионов $\mathrm{Eu}^{3+}$ ортобората $\mathrm{La}_{0.98} \mathrm{Eu}_{0.02} \mathrm{BO}_{3} \quad\left(\lambda_{\max }=614.5 \mathrm{~nm} \quad\left({ }^{5} D_{0} \rightarrow{ }^{7} F_{2}\right)\right)$ в ультрафиолетовой области спектра наблюдается широкая полоса $(\lambda=230-330 \mathrm{~nm})$ с максимумом при $\sim 283 \mathrm{~nm}$ (полоса переноса заряда - ППЗ). СВЛ $\mathrm{La}_{0.98} \mathrm{Eu}_{0.02} \mathrm{BO}_{3}$ содержит также ряд узких полос в диапазоне длин волн 290-500 nm, соответствующих резонансному возбуждению ионов $\mathrm{Eu}^{3+}$. Наиболее интенсивными в длинноволновой области спектра являются полосы, соответствующие резонансному возбуждению ионов $\mathrm{Eu}^{3+}$ $\left(\lambda_{\mathrm{ex}}=394 \mathrm{~nm} \quad\left({ }^{7} F_{0} \rightarrow{ }^{5} L_{6}\right) \quad\right.$ и $\left.\quad 466.5 \mathrm{~nm} \quad\left({ }^{7} F_{0} \rightarrow{ }^{5} D_{2}\right)\right)$ (рис. 6, спектр 1). Спектр возбуждения люминесценции еще одной из наиболее интенсивных полос свечения образцов $\mathrm{La}_{0.98} \mathrm{Eu}_{0.02} \mathrm{BO}_{3}\left(\lambda_{\max }=589.5 \mathrm{~nm}\left({ }^{5} D_{0} \rightarrow{ }^{7} F_{1}\right)\right)$ приведен на рис. 6 , спектр 2. Он идентичен СВЛ полосы с $\lambda_{\max }=614.5 \mathrm{~nm}$ и содержит ПП3 $\left(\lambda_{\mathrm{ex}} \sim 283 \mathrm{~nm}\right)$, a также резонансные полосы $\lambda_{\mathrm{ex}}=394$ и $466.5 \mathrm{~nm}$ (рис. 6, спектр 2). Более того, нормированные интенсивности полос 283, 394, $466.5 \mathrm{~nm}$ для спектров 1 и 2 (рис. 6) близки, они равны 1, 0.32, 0.136 и $1,0.3,0.14$ соответственно. В СВЛ ортоборатов $\mathrm{La}_{0.98-x} \mathrm{Lu}_{x} \mathrm{Eu}_{0.02} \mathrm{BO}_{3}$ при $0 \leq x \leq 0.3$ так же, как и в образцах $\mathrm{La}_{0.98} \mathrm{Eu}_{0.02} \mathrm{BO}_{3}$, наблюдаются узкие резонансные полосы $\lambda_{\text {ex }} \sim 394$ и $466.5 \mathrm{~nm}$, а также полоса переноса заряда $\left(\lambda_{\mathrm{ex}} \sim 283 \mathrm{~nm}\right)$. В качестве примера на рис. 6 , кривая 3 приведен СВЛ образца $\mathrm{La}_{0.68} \mathrm{Lu}_{0.3} \mathrm{Eu}_{0.02} \mathrm{BO}_{3}$. Следует отметить, что при увеличении концентрации $\mathrm{Lu}^{3+}$ от 0 до 30 at.\% интенсивность полос 394 и $466.5 \mathrm{~nm}$ относительно ППЗ увеличивается. Для соединения $\mathrm{La}_{0.68} \mathrm{Lu}_{0.3} \mathrm{Eu}_{0.02} \mathrm{BO}_{3}$ нормированные интенсивно- 
Таблица 2. Максимумы основных полос в спектре возбуждения люминесценции арагонита, ватерита и кальцита и их нормированные интенсивности

\begin{tabular}{c|c|c|c|c|c|c|c|c|c|c|c}
\hline Структура & \multicolumn{3}{|c|}{ Арагонит } & \multicolumn{4}{c|}{ Ватерит } & \multicolumn{4}{c}{ Кальцит } \\
\hline$\lambda_{\mathrm{ex}}, \mathrm{nm}$ & 283 & 394 & 466.5 & 242 & 394 & 466.5 & 469 & 254 & 394 & 466.5 & 469 \\
${ }^{*} I_{\mathrm{Eu}}$ & 1 & 0.53 & 0.23 & 1 & 0.68 & 0.2 & 0.25 & 1 & 0.04 & 0.017 & 0.015
\end{tabular}

Примеч чн и ${ }^{*} I_{\text {Еu }}$ - нормированные интенсивности основных полос в СВЛ.

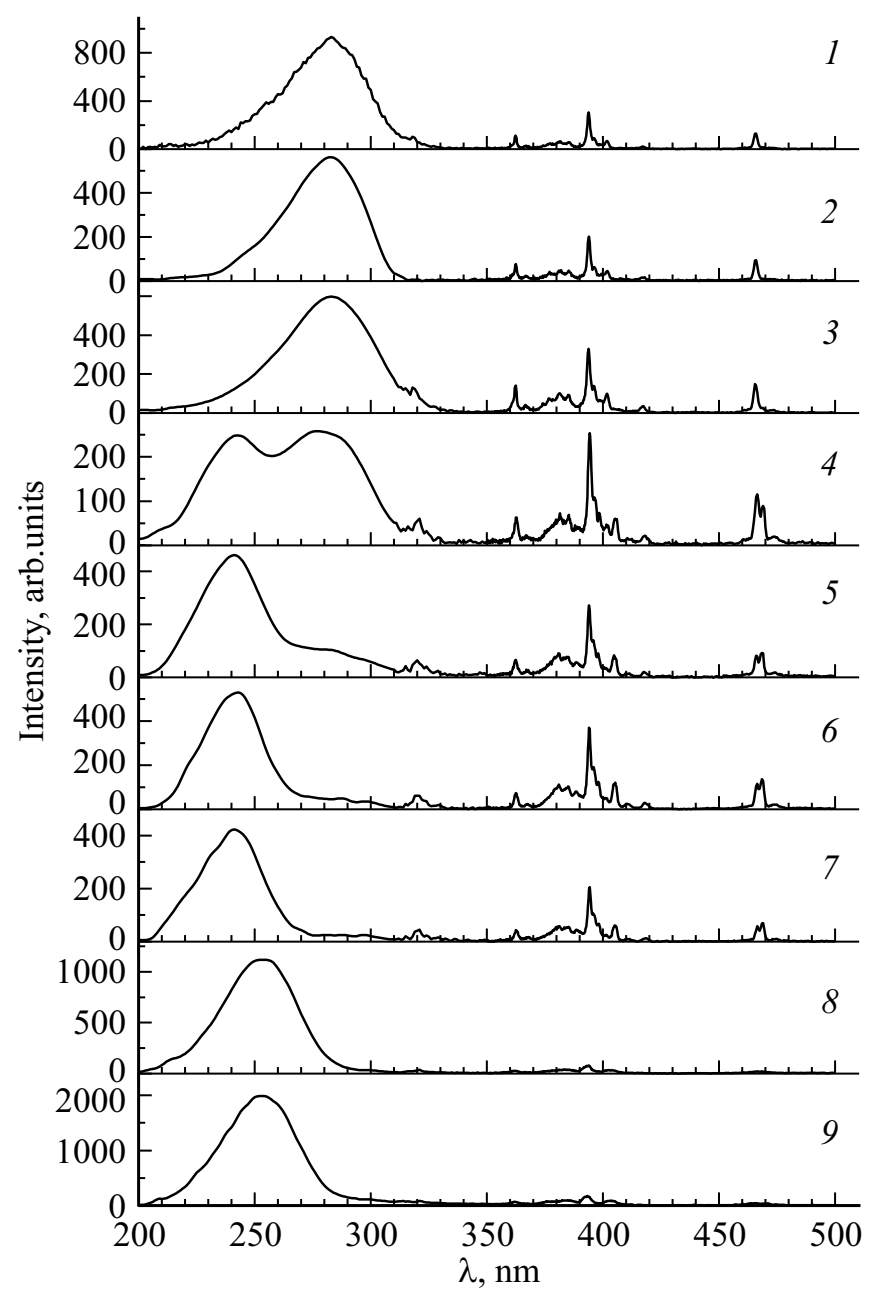

Рис. 6. Спектры возбуждения люминесценции ортоборатов $\mathrm{La}_{0.98-x} \mathrm{Lu}_{x} \mathrm{Eu}_{0.02} \mathrm{BO}_{3} . \quad 1-\mathrm{La}_{0.98} \mathrm{Eu}_{0.02} \mathrm{BO}_{3}$; $2-\mathrm{La}_{0.98} \mathrm{Eu}_{0.02} \mathrm{BO}_{3} ; 3-\mathrm{La}_{0.68} \mathrm{Lu}_{0.3} \mathrm{Eu}_{0.02} \mathrm{BO}_{3} ; 4-$ $\mathrm{La}_{0.48} \mathrm{Lu}_{0.5} \mathrm{Eu}_{0.02} \mathrm{BO}_{3} ; \quad 5-\mathrm{La}_{0.25} \mathrm{Lu}_{0.73} \mathrm{Eu}_{0.02} \mathrm{BO}_{3} ; 6 \quad-$ $\mathrm{La}_{0.18} \mathrm{Lu}_{0.8} \mathrm{Eu}_{0.02} \mathrm{BO}_{3} ; \quad 7-\mathrm{La}_{0.1} \mathrm{Lu}_{0.88} \mathrm{Eu}_{0.02} \mathrm{BO}_{3} ; 8-$ $\mathrm{La}_{0.063} \mathrm{Lu}_{0.917} \mathrm{Eu}_{0.02} \mathrm{BO}_{3} ; 9-\mathrm{La}_{0.05} \mathrm{Lu}_{0.93} \mathrm{Eu}_{0.02} \mathrm{BO}_{3} . \quad 1,3,4-$ $\lambda_{\max }=614.5 \mathrm{~nm} ; 2-\lambda_{\max }=589 . \mathrm{nm} ; 5,6-\lambda_{\max }=593.3 \mathrm{~nm}$; $7,8-\lambda_{\max }=589.8 \mathrm{~nm}$.

сти полос 283, 394, $466.5 \mathrm{~nm}$ равны 1, 0.54, 0.245. Согласно данным рентгенофазового анализа в ортобоpatax $\mathrm{La}_{0.98-x} \mathrm{Lu}_{x} \mathrm{Eu}_{0.02} \mathrm{BO}_{3}$ увеличение концентрации ионов $\mathrm{Lu}^{3+}$ приводит к уменьшению фазы арагонита и увеличению фазы ватерита (табл. 1). Образец $\mathrm{La}_{0.68} \mathrm{Lu}_{0.3} \mathrm{Eu}_{0.02} \mathrm{BO}_{3}$ содержит $73 \%$ арагонита (A) и
27\% ватерита (В). Радикальные изменения спектра возбуждения люминесценции наблюдаются в образце $\mathrm{La}_{0.48} \mathrm{Lu}_{0.5} \mathrm{Eu}_{0.02} \mathrm{BO}_{3} \quad$ (55\% A и $\left.45 \% \mathrm{~B}\right)$ (табл. 1). СВЛ этого образца содержит две коротковолновые полосы $\lambda_{\mathrm{ex}} \sim 242$ и $283 \mathrm{~nm}$ примерно одинаковой интенсивности и резонансные полосы 394, 466.5 и $469 \mathrm{~nm}$ (рис. 6, спектр 4). Полоса $\lambda_{\mathrm{ex}} \sim 242 \mathrm{~nm}$ соответствует полосе переноса заряда в ватеритной модификации $\mathrm{LuBO}_{3}(\mathrm{Eu})$.

При дальнейшем увеличении концентрации ионов $\mathrm{Lu}^{3+}$ интенсивность коротковолновой полосы $\lambda_{\mathrm{ex}} \sim 283 \mathrm{~nm}$ уменьшается, а в образцах, содержащих 80 at.\% $\mathrm{Lu}^{3+}$, в спектре возбуждения люминесценции в ультрафиолетовой области спектра наблюдается полоса с $\lambda_{\mathrm{ex}} \sim 242 \mathrm{~nm}$, а также резонансные полосы 394, 466.5 и $469 \mathrm{~nm}$ (рис. 6, спектры 5, 6). В СВЛ образцов $\mathrm{La}_{0.18} \mathrm{Lu}_{0.8} \mathrm{Eu}_{0.02} \mathrm{BO}_{3}$, которые содержат 96\% В и 4\% А, нормированные интенсивности полос 283, 394, $466.5 \mathrm{~nm}$ равны 1, 0.68, 0.2 (табл. 1 и 2). Полоса с максимумом при $\sim 242 \mathrm{~nm}$ наблюдается также в спектрах возбуждения люминесценции образцов $\mathrm{La}_{0.98-x} \mathrm{Lu}_{x} \mathrm{Eu}_{0.02} \mathrm{BO}_{3}$, имеющих концентрацию ионов $\mathrm{Lu}^{3+} 88$ и 90.5 at.\% (рис. 6, спектр 7). В этих образцах, содержащих 98\% В, 2\% К и 64\% В, 36\%К (табл. 1), наблюдаются также полосы 394, 466.5 и $469 \mathrm{~nm}$.

При дальнейшем увеличении концентрации ионов $\mathrm{Lu}^{3+}$ максимум полосы переноса заряда сдвигается в область больших длин волн (рис. 6, спектры 8,9). Для образцов, легированных 91.7, 93 и 98 at.\% $\mathrm{Lu}^{3+}$ и содержащих 13\% В, 87\% К; 100\% К и 100\% К соответственно (табл. 1), ППЗ имеет максимум при $\sim 254 \mathrm{~nm}$. Нормированные интенсивности полос 254, 394 и $466.5 \mathrm{~nm}$ для кальцитной модификации равны $1,0.04$ и 0.017 , соответственно (табл. 2). Приведенные данные свидетельствуют о том, что при увеличении количества фазы кальцита в СВЛ увеличивается интенсивность коротковолновой полосы (ППЗ) с максимумом при $\sim 254 \mathrm{~nm}$, интенсивность которой в фазе кальцита в $\sim 25-30$ раз больше наиболее интенсивной резонансной полосы $394 \mathrm{~nm}$.

В табл. 2 приведены максимумы основных полос в спектре возбуждения люминесценции $\left(\lambda_{\mathrm{ex}}\right)$ наиболее интенсивных полос свечения различных структурных модификаций соединений $\mathrm{La}_{0.98-x} \mathrm{Lu}_{x} \mathrm{Eu}_{0.02} \mathrm{BO}_{3}$, а также их нормированные интенсивности. Как видно из таблицы, в СВЛ арагонита отсутствует полоса с максимумом при 469 nm, а максимумы полос переноса заряда для фаз арагонита, ватерита и кальцита находятся при длинах волн 283, 242 и $254 \mathrm{~nm}$ соответственно. Следует также 

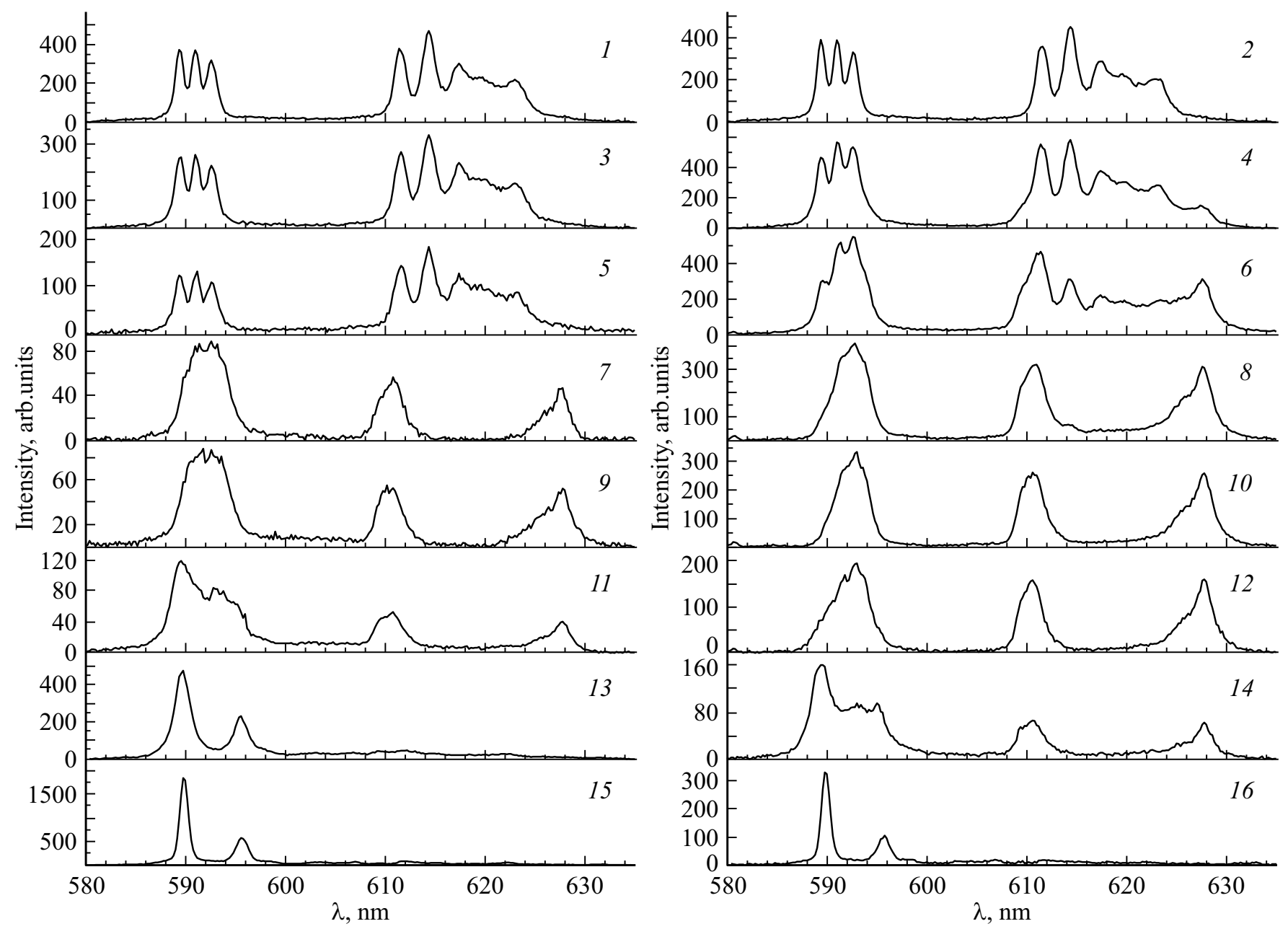

Рис. 7. Спектры люминесценции ортоборатов $\mathrm{La}_{0.98-x} \mathrm{Lu}_{x} \mathrm{Eu}_{0.02} \mathrm{BO}_{3} .1,2-\mathrm{La}_{0.98} \mathrm{Eu}_{0.02} \mathrm{BO}_{3} ; 3,4-\mathrm{La}_{0.78} \mathrm{Lu}_{0.2} \mathrm{Eu}_{0.02} \mathrm{BO}_{3}$; 5, $6-\mathrm{La}_{0.48} \mathrm{Lu}_{0.5} \mathrm{Eu}_{0.02} \mathrm{BO}_{3} ; 7,8-\mathrm{La}_{0.25} \mathrm{Lu}_{0.73} \mathrm{Eu}_{0.02} \mathrm{BO}_{3} ; 9,10-\mathrm{La}_{0.1} \mathrm{Lu}_{0.88} \mathrm{Eu}_{0.02} \mathrm{BO}_{3} ; 11,12-\mathrm{La}_{0.075} \mathrm{Lu}_{0.905} \mathrm{Eu}_{0.02} \mathrm{BO}_{3} ; 13,14-$ $\mathrm{La}_{0.063} \mathrm{Lu}_{0.917} \mathrm{Eu}_{0.02} \mathrm{BO}_{3} ; 15,16-\mathrm{Lu}_{0.98} \mathrm{Eu}_{0.02} \mathrm{BO}_{3} .1,3,5$ и $7-\lambda_{\text {ех }}=283 \mathrm{~nm} ; 9$ и $11-\lambda_{\text {ех }}=242 \mathrm{~nm} ; 13$ и $15-\lambda$ ех $=254 \mathrm{~nm}$; $2,4,6,8,10,12,14$ и $16-\lambda_{\text {ex }}=394 \mathrm{~nm}$.

отметить, что в структурах арагонита и ватерита нормированные интенсивности полос близки, в то время как для структуры кальцита интенсивность полосы переноса заряда значительно выше резонансных полос. Наличие доминирующей коротковолновой полосы является важной особенностью СВЛ-образцов $\mathrm{LuBO}_{3}$ и $\mathrm{InBO}_{3}$, имеющих структуру кальцита.

\section{2. Спектры люминесценции}

Спектры люминесценции (СЛ) соединений $\mathrm{La}_{0.98-x} \mathrm{Lu}_{x} \mathrm{Eu}_{0.02} \mathrm{BO}_{3} \quad(x=0,0.2$. 0,3, 0.5, 0.88, 0.905, 0.917 и 0.98$)$ в спектральном диапазоне $580-635 \mathrm{~nm}$ при возбуждении светом $\left(\lambda_{\mathrm{ex}}=394 \mathrm{~nm}\right)$, соответствующим резонансному возбуждению ионов $\mathrm{Eu}^{3+}$, и в максимуме полосы переноса заряда $\left(\lambda_{\mathrm{ex}} \sim 283-242 \mathrm{~nm}\right)$, представлены на рис. 7. Спектры люминесценции приповерхностного слоя $\left(\lambda_{\mathrm{ex}}=283 \mathrm{~nm}\right)$, и объема $\left(\lambda_{\mathrm{ex}}=394 \mathrm{~nm}\right) \quad$ ортобората $\mathrm{La}_{0.98} \mathrm{Eu}_{0.02} \mathrm{BO}_{3}$, который имеет согласно данным рентгенофазового анализа структуру арагонита (табл. 1), совпадают (рис. 7, спектры 1 и 2). Они содержат полосы с $\lambda_{\max }=589.4,591$ и $592.6 \mathrm{~nm}$, соответствующие электронному переходу ${ }^{5} D_{0} \rightarrow{ }^{7} F_{1}$, а также полосы $611.6,614.5,617.4,619.8$, 621.3 и $623 \mathrm{~nm} \quad\left({ }^{5} D_{0} \rightarrow{ }^{7} F_{2}\right) \quad$ (рис. 8). В то же время, в исследованном в работах [29-31] спектре люминесценции (СЛ) $\mathrm{LaBO}_{3}(\mathrm{Eu})$ в диапазоне длин волн 589-593 nm наблюдается одна полоса, а в интервале 610-623 nm также наблюдается широкая полоса и плечо на длинноволновом крае этой полосы. Такое различие в СЛ, полученных в настоящей работе и в работах [29-31] связано, скорее всего, с недостаточно высоким спектральным разрешением, используемым при регистрации СЛ в этих работах.

Спектры люминесценции соединений $\mathrm{La}_{0.98-x} \mathrm{Lu}_{x} \mathrm{Eu}_{0.02} \mathrm{BO}_{3} \quad$ при $\quad 0 \leq x<0.15$, имеющих согласно данным рентгенофазового анализа структуру арагонита (табл. 1), идентичны. В этих образцах спектры люминесценции приповерхностного слоя 
$E, \mathrm{eV}$

$\begin{array}{lllllllll}2.12 & 2.10 & 2.08 & 2.06 & 2.04 & 2.02 & 2.00 & 1.98 & 1.96\end{array}$

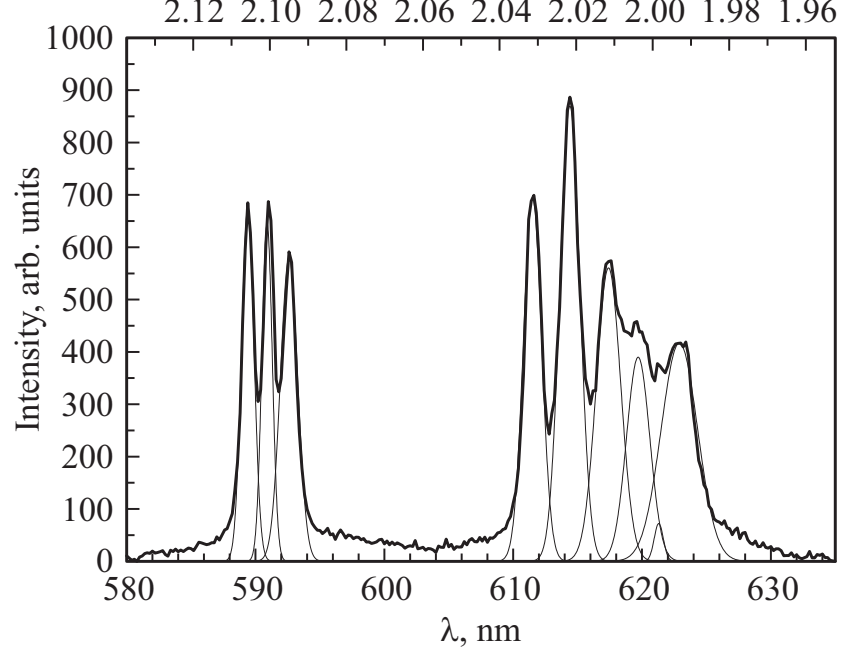

Рис. 8. Разложение полос 588-596 и 610-635 nm (рис. 7, спектр 2) на составляющие. При разложении спектра использовалась энергетическая шкала, после разложения спектра осуществлялся переход от $\mathrm{eV}$ к $\mathrm{nm}$.

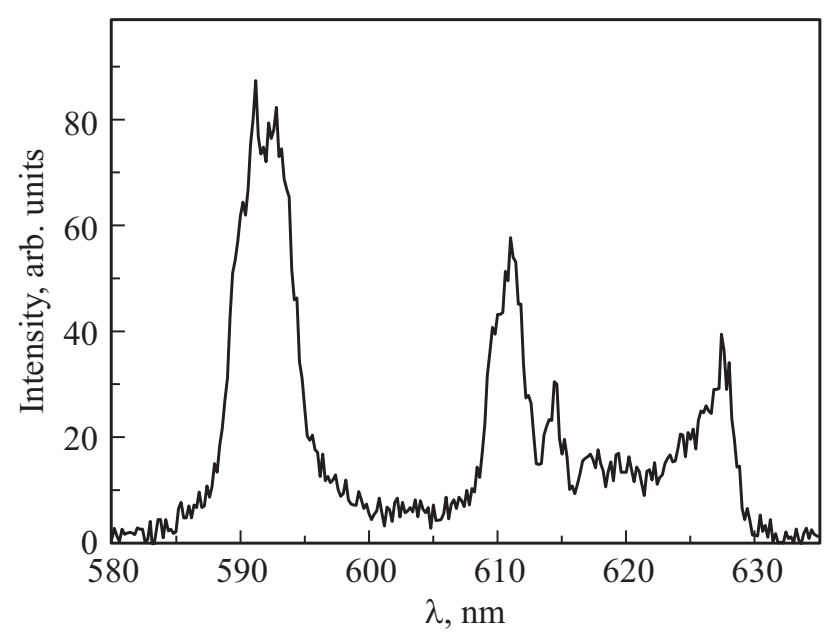

Pис. 9. Спектр люминесценции ортобората $\mathrm{La}_{0.48} \mathrm{Lu}_{0.5} \mathrm{Eu}_{0.02} \mathrm{BO}_{3}$ при возбуждении светом с $\lambda_{\mathrm{ex}}=242 \mathrm{~nm}$.

$\left(\lambda_{\mathrm{ex}}=283 \mathrm{~nm}\right), \quad$ и $\quad$ объема образца $\left(\lambda_{\mathrm{ex}}=394 \mathrm{~nm}\right)$ совпадают, как и в образце $\mathrm{La}_{0.98} \mathrm{Eu}_{0.02} \mathrm{BO}_{3}$ (рис. 7, спектры 1 и 2).

В образцах $\mathrm{La}_{0.78} \mathrm{Lu}_{0.2} \mathrm{Eu}_{0.02} \mathrm{BO}_{3}$, содержащих $89 \%$ арагонита (А) и $11 \%$ ватерита (В) (табл. 1), спектр люминесценции приповерхностного слоя $\left(\lambda_{\text {ех }}=283 \mathrm{~nm}\right)$ содержит полосы, характерные для структуры арагонита $\mathrm{LaBO}_{3}(\mathrm{Eu})$ (рис. 7, спектр 3). В то же время в спектре люминесценции объема этого образца $\left(\lambda_{\mathrm{ex}}=394 \mathrm{~nm}\right)$ наряду с полосами, характерными для структуры арагонита, появляется полоса $\left(\lambda_{\max } \sim 628 \mathrm{~nm}\right)$, соответствующая ватеритной структуре $\mathrm{LuBO}_{3}(\mathrm{Eu})$. Кроме этого, возникают изменения в соотношении интенсивностей полос с $\lambda_{\max }=589.4,591$ и $592.6 \mathrm{~nm}$ (рис. 7, спектр 4). Таким образом, формирование фазы ватерита происходит в объеме микрокристаллов, имеющих структуру арагонита. Еще большие изменения в СЛ объема образца $\left(\lambda_{\mathrm{ex}}=394 \mathrm{~nm}\right)$ наблюдаются в соединениях $\mathrm{La}_{0.68} \mathrm{Lu}_{0.3} \mathrm{Eu}_{0.02} \mathrm{BO}_{3} \quad(73 \% \mathrm{~A}, 26 \% \mathrm{~B})$ и $\mathrm{La}_{0.48} \mathrm{Lu}_{0.5} \mathrm{Eu}_{0.02} \mathrm{BO}_{3}(55 \% \mathrm{~A}, 45 \% \mathrm{~B})$. В этих образцах увеличивается интенсивность полосы $\sim 628 \mathrm{~nm}$, а также происходят изменения в области длин волн $598-596 \mathrm{~nm}$ (рис. 7, кривая 6). В то же время, в спектре люминесценции приповерхностного слоя $\left(\lambda_{\mathrm{ex}}=283 \mathrm{~nm}\right)$ наблюдаются только полосы, характерные для структуры арагонита (рис. 7, спектр 5). Как отмечалось, в спектре возбуждения люминесценции образцов $\mathrm{La}_{0.48} \mathrm{Lu}_{0.5} \mathrm{Eu}_{0.02} \mathrm{BO}_{3}$ в ультрафиолетовой области спектра наблюдается две полосы с максимумами 242 и $283 \mathrm{~nm}$ (рис. 6, спектр 4). Коротковолновая полоса $\lambda_{\mathrm{ex}}=242 \mathrm{~nm}$ соответствует ППЗ в ватеритной модификации $\mathrm{LuBO}_{3}(\mathrm{Eu})$. Важно отметить, что СЛ приповерхностного слоя $\mathrm{La}_{0.48} \mathrm{Lu}_{0.5} \mathrm{Eu}_{0.02} \mathrm{BO}_{3}$ при возбуждении светом с $\lambda_{\mathrm{ex}}=242 \mathrm{~nm}$ содержит полосы, характерные для ватеритной модификации (рис. 9). Как отмечалось, при дальнейшем увеличении концентрации ионов $\mathrm{Lu}^{3+}$ в коротковолновой области спектра возбуждения люминесценции наблюдается значительное увеличение интенсивности полосы с $\lambda_{\mathrm{ex}}=242 \mathrm{~nm}$ (рис. 6, спектр 5). В этих образцах полосы, характерные для фазы ватерита появляются не только в СЛ объема, но и в приповерхностных слоях образца. В спектрах люминесценции приповерхностного слоя $\left(\lambda_{\mathrm{ex}}=242 \mathrm{~nm}\right)$ и объема $\left(\lambda_{\mathrm{ex}}=394 \mathrm{~nm}\right)$ ортоборатов $\mathrm{La}_{0.35} \mathrm{Lu}_{0.63} \mathrm{Eu}_{0.02} \mathrm{BO}_{3}$ (29\% А и $71 \%$ B $), \mathrm{La}_{0.25} \mathrm{Lu}_{0.73} \mathrm{Eu}_{0.02} \mathrm{BO}_{3}(20 \%$ А и $80 \%$ B) и $\mathrm{La}_{0.18} \mathrm{Lu}_{0.8} \mathrm{Eu}_{0.02} \mathrm{BO}_{3}(4 \% \mathrm{~A}$ и $96 \% \mathrm{~B})$ наблюдаются полосы, характерные для ватеритной модификации соединений $\mathrm{LuBO}_{3}(\mathrm{Eu})$ (рис. 7, спектры 7, 8).

Согласно данным рентгенофазового анализа (табл. 1) в ортоборатах $\mathrm{La}_{0.98-x} \mathrm{Lu}_{x} \mathrm{Eu}_{0.02} \mathrm{BO}_{3}$ при $0.84<x \leq 0.98$ наблюдается последовательная смена 3 типов структурных модификаций. Вначале ортобораты имеют структуру ватерита, затем становятся двухфазными - наряду со структурой ватерита появляется фаза кальцита. При $0.93<x \leq 0.98$ весь объем образца имеет структуру кальцита (К) (табл. 1). Спектры люминесценции приповерхностного слоя $\left(\lambda_{\mathrm{ex}}=242 \mathrm{~nm}\right)$, и объема $\left(\lambda_{\text {ex }}=394 \mathrm{~nm}\right)$ соединения $\mathrm{La}_{0.1} \mathrm{Lu}_{0.88} \mathrm{Eu}_{0.02} \mathrm{BO}_{3}$ $(98 \%$ В и $2 \%$ К) содержат полосы, характерные для структуры ватерита ортобората $\mathrm{LuBO}_{3}(\mathrm{Eu})$ (рис. 7, спектры 9,10). При увеличении концентрации ионов $\mathrm{Lu}^{3+}$ количество фазы кальцита увеличивается и в спектре люминесценции приповерхностного слоя образца $\mathrm{La}_{0.075} \mathrm{Lu}_{0.905} \mathrm{Eu}_{0.02} \mathrm{BO}_{3}(64 \% \mathrm{~B}, 34 \% \mathrm{~K})$ появляются полосы $\lambda_{\max }=589.8$ и $595.7 \mathrm{~nm}$, характерные для кальцитной модификации $\mathrm{LuBO}_{3}(\mathrm{Eu})$ (рис. 7, спектр 11). В то же время, СЛ объема этого образца содержит только полосы, характерные для ватеритной структуры $\mathrm{LuBO}_{3}(\mathrm{Eu})$ (рис. 7, спектр 12). Таким образом, образование фазы кальцита в образцах, имеющих структуру ватерита, происходит в приповерхностном слое образца. Дальнейшее увеличение концентрации $\mathrm{Lu}^{3+}$ 
приводит к возникновению в СЛ объема образцов полос, характерных для кальцитной модификации. Спектр люминесценции объема $\mathrm{La}_{0.063} \mathrm{Lu}_{0.917} \mathrm{Eu}_{0.02} \mathrm{BO}_{3} \quad(13 \% \mathrm{~B}$, $87 \%$ K) содержит полосы, характерные для ватеритной и кальцитной структур (рис. 7, спектр 14). При этом СЛ приповерхностного слоя этого образца содержит только полосы кальцитной фазы $\mathrm{LuBO}_{3}(\mathrm{Eu})$ (рис. 7, спектр 13). Спектры люминесценции приповерхностного слоя и объема соединений $\mathrm{La}_{0.05} \mathrm{Lu}_{0.93} \mathrm{Eu}_{0.02} \mathrm{BO}_{3}$ и $\mathrm{Lu}_{0.98} \mathrm{Eu}_{0.02} \mathrm{BO}_{3}$, которые имеют структуру кальцита (табл. 1), содержат только полосы кальцитной модификации $\mathrm{LuBO}_{3}(\mathrm{Eu})$ (рис. 7, спектры 15, 16).

На основании сопоставления результатов рентгенофазового анализа и спектральных исследований можно сделать вывод о том, что наблюдается соответствие между структурой и спектральными характеристиками ортоборатов $\mathrm{La}_{0.98-x} \mathrm{Lu}_{x} \mathrm{Eu}_{0.02} \mathrm{BO}_{3}$. Увеличение $x$ приводит к последовательной смене различных структурных модификаций. При $0 \leq x<0.15$ соединение имеет структуру арагонита и в СЛ наблюдаются полосы, соответствующие структуре арагонита (рис. 7, спектры 1,2). При $0.15 \leq x \leq 0.84$ образцы являются двухфазными, они содержат фазы арагонита и ватерита, и СЛ этих образцов содержит полосы арагонитной и ватеритной модификаций (рис. 7, спектры 3-8). При $0.8<x<0.88$ ортобораты имеют структуру ватерита и в СЛ наблюдаются полосы ватеритной модификации (рис. 7, спектры 9, 10). При $0.88<x<0.93$ наблюдаются фазы ватерита и кальцита и СЛ содержит полосы, соответствующие структурам ватерита и кальцита (рис. 7, спектры 11-14). При $0.93 \leq x \leq 0.98$ образцы имеют структуру кальцита, и СЛ содержит полосы кальцитной фазы $\mathrm{LuBO}_{3}(\mathrm{Eu})$ (рис. 7, спектры 15, 16).

Важно отметить, что при увеличении концентрации ионов $\mathrm{Lu}^{3+}$ фаза ватерита формируется в объеме образцов $\mathrm{La}_{0.98-x} \mathrm{Lu}_{x} \mathrm{Eu}_{0.02} \mathrm{BO}_{3}$, имеющих структуру арагонита. При дальнейшем увеличении концентрации ионов $\mathrm{Lu}^{3+}$ фаза ватерита образуется и на поверхности образца. Этот процесс подобен образованию фазы ватерита в объеме крупных микрокристаллов $\mathrm{Lu}_{0.99-x} \mathrm{RE}_{x} \mathrm{Eu}_{0.01} \mathrm{BO}_{3}$ (где $\mathrm{RE}=\mathrm{Gd}, \mathrm{Eu}, \mathrm{Tb}, \mathrm{Y})$, имеющих структуру кальцита $[23,24]$.

В то же время образование кальцита при $0.88<x<0.93$ в ортоборатах $\mathrm{La}_{0.98-x} \mathrm{Lu}_{x} \mathrm{Eu}_{0.02} \mathrm{BO}_{3}$, которые имеют структуру ватерита, происходит в приповерхностных областях образца, так же, как и в соединениях $\mathrm{Lu}_{0.98-x} \mathrm{In}_{x} \mathrm{Eu}_{0.02} \mathrm{BO}_{3}$ [22].

На рис. 10 приведены зависимости нормированных интегральных интенсивностей свечения (площадей под кривыми люминесценции) ортоборатов $\mathrm{La}_{0.98-x} \mathrm{Lu}_{x} \mathrm{Eu}_{0.02} \mathrm{BO}_{3} \quad$ в диапазоне $2.138-1.953 \mathrm{eV}$ $(580-635 \mathrm{~nm})$ от концентрации ионов $\mathrm{Lu}(0 \leq x \leq 0.98)$ при возбуждении в максимуме полосы переноса заряда $\left(\lambda_{\mathrm{ex}} \sim 283-242 \mathrm{~nm}\right)$ ( $\left.\mathrm{S}_{\text {Ппз }}\right)$ и при резонансном возбуждении ионов $\mathrm{Eu}^{3+}\left(\lambda_{\mathrm{ex}}=394 \mathrm{~nm}\right)\left(\mathrm{S}_{394}\right)$. Интегральная интенсивность свечения при возбуждении в ППЗ (рис. 10, кривая 1) при увеличении концентрации $\mathrm{Lu}$

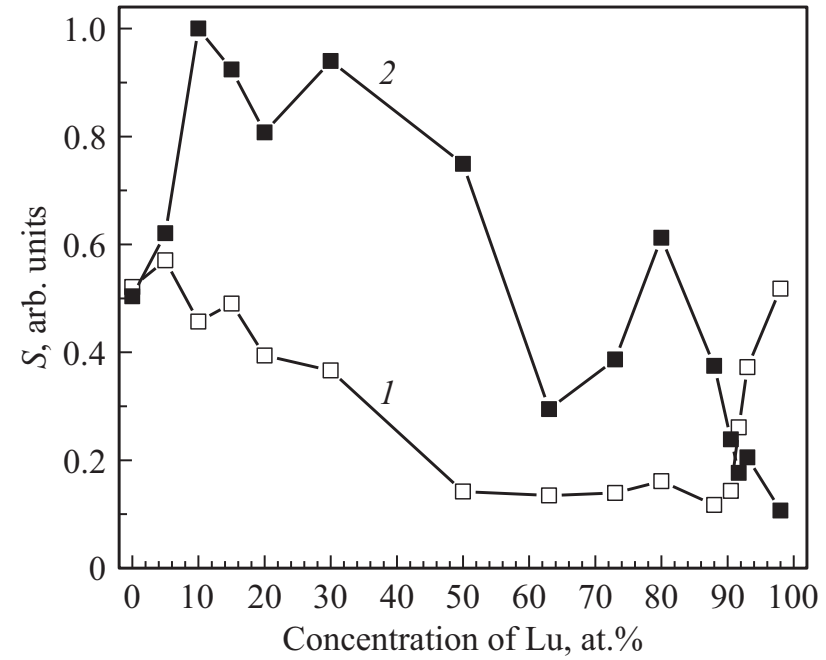

Рис. 10. Зависимости от концентрации ионов $\mathrm{Lu}$ интегральной интенсивности свечения - $S$ (площади под кривыми люминесценции) ортоборатов $\mathrm{La}_{0.98-x} \mathrm{Lu}_{x} \mathrm{Eu}_{0.02} \mathrm{BO}_{3}$ в диапазоне $2.138-1.953 \mathrm{eV} \quad(580-635 \mathrm{~nm}) .1$ - при возбуждении в максимуме полосы переноса заряда ППЗ $S_{\text {Ппз }}\left(\lambda_{\mathrm{ex}} \sim 283-242 \mathrm{~nm}\right) ; 2-$ при возбуждении светом $\lambda_{\mathrm{ex}}=394 \mathrm{~nm}-S_{394}$.

$(0 \leq x<0.5)$ уменьшается, в диапазоне $0.5 \leq x \leq 0.905$ $\mathrm{S}_{\text {Ппз }}$ остается практически без изменения, а при $0.905<x \leq 0.98$ наблюдается рост ППЗ. Интегральные интенсивности свечения при возбуждении в полосе переноса заряда при $0 \leq x \leq 0.1$ и $x=0.98$ близки.

Интегральная интенсивность свечения при резонансном возбуждении ионов $\mathrm{Eu}^{3+}$ в соединении $\mathrm{La}_{0.98-x} \mathrm{Lu}_{x} \mathrm{Eu}_{0.02} \mathrm{BO}_{3} \quad\left(\mathrm{~S}_{394}\right)$ увеличивается при росте концентрации $\mathrm{Lu}$, достигает максимального значения при $x=0.1$, а затем уменьшается. При $x=0.8$ наблюдается второй максимум на зависимости $\mathrm{S}_{394}$ от концентрации лютеция (рис. 10, кривая 2). Следует отметить, что максимальное значение $\mathrm{S}_{394}$ в 2 раза превосходит значение $\mathrm{S}_{394}$ при $x=0$.

Как известно, электронные переходы между состояниями свободных ионов $\mathrm{Eu}^{3+}$, принадлежащих одной, в нашем случае $4 f^{n}$-конфигурации, запрещены по четности $[14,15]$. Под действием кристаллического поля этот запрет частично снимается. При замещении ионов $\mathrm{La}^{3+}$, имеющих ионный радиус $1.114 \AA$, ионами $\mathrm{Lu}^{3+}$, имеющих значительно меньший ионный радиус $(0.867 \AA)[38]$, величина кристаллического поля в $\mathrm{La}_{0.98-x} \mathrm{Lu}_{x} \mathrm{Eu}_{0.02} \mathrm{BO}_{3}$ возрастает, что приводит к увеличению интенсивности свечения $\mathrm{Eu}^{3+}$ при резонансном возбуждении (рис. 10, кривая 2).

Важно отметить, что для образцов $\mathrm{La}_{0.98-x} \mathrm{Lu}_{x} \mathrm{Eu}_{0.02} \mathrm{BO}_{3}$, имеющих при $0 \leq x<0.15$ структуру арагонита (табл. 1), максимум интегральной интенсивности свечения при резонансном возбуждении ионов $\mathrm{Eu}^{3+}\left(\lambda_{\mathrm{ex}}=394 \mathrm{~nm}\right) \quad\left(\mathrm{S}_{394}\right)$ наблюдается при $x=0.1$. Это свидетельствует о том, что увеличение $\mathrm{S}_{394}$ 
при $x=0.1$ не связано со структурными преобразованиями, а определяется изменением концентрации ионов $\mathrm{Lu}^{3+}$ в арагонитной модификации $\mathrm{La}_{0.98-x} \mathrm{Lu}_{x} \mathrm{Eu}_{0.02} \mathrm{BO}_{3}$.

Рассмотрим твердый раствор $\mathrm{Lu}_{0.98-y} \mathrm{La}_{y} \mathrm{Eu}_{0.02} \mathrm{BO}_{3}$. Это соединение, согласно изложенным выше данным, при $0 \leq y \leq 0.05$ имеет структуру кальцита. При $0.05<y \leq 0.1$ соединение является двухфазным - содержит фазы кальцита и ватерита, а при $0.1<y<0.18$ имеет структуру ватерита (табл. 1). Поскольку синтезированные при $970^{\circ} \mathrm{C}$ соединения $\mathrm{LuBO}_{3}$ и $\mathrm{LaBO}_{3}$ имеют структуры кальцита и арагонита соответственно $[12,1,25]$, то можно было бы ожидать, что в синтезированных при $970^{\circ} \mathrm{C}$ соединениях $\mathrm{Lu}_{0.98-y} \mathrm{La}_{y} \mathrm{Eu}_{0.02} \mathrm{BO}_{3}$ увеличение $y$ будет приводить к постепенному уменьшению количества фазы кальцита и увеличению фазы арагонита. Однако приведенные экспериментальные данные по исследованию фазообразования в соединениях $\mathrm{Lu}_{0.98-y} \mathrm{La}_{y} \mathrm{Eu}_{0.02} \mathrm{BO}_{3}$ не подтверждают это предположение. При увеличении концентрации $\mathrm{La}^{3+}$ происходит образование фазы ватерита, то есть в твердом растворе $\mathrm{Lu}_{0.98-y} \mathrm{La}_{y} \mathrm{Eu}_{0.02} \mathrm{BO}_{3}$ при $0 \leq y \leq 0.1$ ионы $\mathrm{La}^{3+}$ играют такую же фазообразующую роль, как и ионы $\mathrm{RE}^{3+}(\mathrm{RE}=\mathrm{Eu}, \mathrm{Gd}, \mathrm{Tb}, \mathrm{Y})$ в ортоборате $\mathrm{Lu}_{0.98-y} \mathrm{RE}_{y} \mathrm{Eu}_{0.02} \mathrm{BO}_{3}$. Различное воздействие на фазообразование $\mathrm{Lu}_{0.98-y} \mathrm{RE}_{y} \mathrm{Eu}_{0.02} \mathrm{BO}_{3}$ ионов $\mathrm{La}^{3+}$ и $\mathrm{RE}^{3+}$ проявляется при $0.18<y \leq 0.98$. В этом диапазоне концентраций $y$ соединение $\mathrm{Lu}_{0.98-y} \mathrm{RE}_{y} \mathrm{Eu}_{0.02} \mathrm{BO}_{3}$ имеет структуру ватерита, а в ортоборате $\mathrm{Lu}_{0.98-y} \mathrm{La}_{y} \mathrm{Eu}_{0.02} \mathrm{BO}_{3}$ при увеличении $y$ наблюдается уменьшение количества фазы ватерита и увеличению фазы арагонита.

Можно было бы предположить, что наличие 2 at.\% ионов $\mathrm{Eu}^{3+}$ в ортоборате $\mathrm{Lu}_{0.98-y} \mathrm{La}_{y} \mathrm{Eu}_{0.02} \mathrm{BO}_{3}$, которые используются в качестве оптически активных и структурно-чувствительных меток, приводит к образованию фазы ватерита при $0.05 \leq y \leq 0.1$. Если бы это предположение было верно, то соединение $\mathrm{Lu}_{0.9} \mathrm{La}_{0.1} \mathrm{BO}_{3}$ должно было бы иметь структуру арагонита. Однако, согласно данным рентгенофазового анализа образец $\mathrm{Lu}_{0.9} \mathrm{La}_{0.1} \mathrm{BO}_{3}$ содержит 93\% ватерита и 7\% кальцита, а образец $\mathrm{Lu}_{0.88} \mathrm{La}_{0.1} \mathrm{Eu}_{0.02} \mathrm{BO}_{3}$ содержит 98\% ватерита и $2 \%$ кальцита (табл. 1). Эти данные свидетельствуют о том, что наличие 2 at.\% ионов $\mathrm{Eu}^{3+}$ в ортоборате $\mathrm{Lu}_{0.98-y} \mathrm{La}_{y} \mathrm{Eu}_{0.02} \mathrm{BO}_{3}$ не оказывают значительного влияния на формирование структурного состояния в этих соединениях.

\section{7. Заключение}

В настоящей работе проведены исследования структуры, морфологии, ИК-спектров, а также спектров возбуждения люминесценции и спектров люминесценции приповерхностного слоя и объема синтезированных при $970^{\circ} \mathrm{C}$ ортоборатов $\mathrm{La}_{0.98-x} \mathrm{Lu}_{x} \mathrm{Eu}_{0.02} \mathrm{BO}_{3}$ при $0 \leq x \leq 0.98$.

Установлено однозначное соответствие между структурной модификацией и спектральными характеристи- ками фотолюминесценции и ИК-спектрами ортоборатов. Исследование спектров люминесценции при разных длинах волн возбуждающего света позволило получить информацию о структуре приповерхностного слоя и объема исследованных образцов.

Показано, что в ортоборатах $\mathrm{La}_{0.98-x} \mathrm{Lu}_{x} \mathrm{Eu}_{0.02} \mathrm{BO}_{3}$ увеличение концентрации ионов $\mathrm{Lu}^{3+}$ приводит к последовательному изменению их структурного состояния и спектральных характеристик.

- При $0 \leq x \leq 0.1$ соединения являются однофазными и имеют структуру арагонита (пр.гр. Pnam). Соответствующие структуре арагонита спектры люминесценции ионов $\mathrm{Eu}^{3+}$ в приповерхностном слое и объеме микрокристаллов этих образцов содержат полосы с $\lambda_{\max }=589.4,591$ и $592.6 \mathrm{~nm}$, соответствующие электронному переходу ${ }^{5} D_{0} \rightarrow{ }^{7} F_{1}$, а также полосы 611.6, 614.5, 617.4, 619.8, 621.3 и $623 \mathrm{~nm}\left({ }^{5} D_{0} \rightarrow{ }^{7} F_{2}\right)$. В ИК-спектрах наблюдаются полосы поглощения 592, 612, 721, 789, 939 и $1302 \mathrm{~cm}^{-1}$, соответствующие фазе арогонита.

- При $0.15 \leq x \leq 0.8$ образцы $\mathrm{La}_{0.98-x} \mathrm{Lu}_{x} \mathrm{Eu}_{0.02} \mathrm{BO}_{3}$ являются двухфазными, они содержат фазы арагонита и ватерита, в спектрах люминесцеции и ИК-спектрах наблюдаются полосы, характерные для структур арагонита $\mathrm{La}_{0.98} \mathrm{Eu}_{0.02} \mathrm{BO}_{3}$ и ватерита $\mathrm{LuBO}_{3}(\mathrm{Eu})$.

- При $0.8<x<0.88$ ортобораты имеют структуру ватерита (пр.гр. $\left.P 6_{3} / m m c\right)$. Спектры люминесценции ионов $\mathrm{Eu}^{3+}$ в приповерхностном слое и объеме микрокристаллов этих образцов идентичны и содержат полосы 588-596, 608-613 и 624-632 nm, характерные для ватеритной модификации $\mathrm{LuBO}_{3}(\mathrm{Eu})$. В ИК-спектрах фазы ватерита наблюдаются полосы поглощения 571, $717,879,934$ и $1103 \mathrm{~cm}^{-1}$.

- При $0.88<x<0.93$ образцы $\mathrm{La}_{0.98-x} \mathrm{Lu}_{x} \mathrm{Eu}_{0.02} \mathrm{BO}_{3}$ являются двухфазными, они содержат фазы ватерита и кальцита, в спектрах люминесценции и ИК-спектрах наблюдаются полосы, характерные для ватеритной и кальцитной модификаций этих образцов.

- При $0.93 \leq x \leq 0.98$ ортобораты являются однофазными и имеют структуру кальцита (пр.гр. $R \overline{3} c$ ). В спектрах люминесценции и ИК-спектрах наблюдаются полосы, характерные для кальцитной модификации $\mathrm{LuBO}_{3}(\mathrm{Eu})$. Спектры люминесценции приповерхностного слоя и объема микрокристаллов этих образцов содержат 2 узкие полосы с $\lambda_{\max }=589.8$ и $595.7 \mathrm{~nm}$ $\left({ }^{5} D_{0} \rightarrow{ }^{7} F_{1}\right)$, а в ИК-спектрах наблюдаются полосы поглощения 629, 747, 774 и $1239 \mathrm{~cm}^{-1}$.

Установлено, что по мере увеличения $x$ образование фазы ватерита в образцах $\mathrm{La}_{0.98-x} \mathrm{Lu}_{x} \mathrm{Eu}_{0.02} \mathrm{BO}_{3}$, исходно имеющих структуру арагонита, происходит вначале в объеме образцов. Дальнейшее увеличение концентрации ионов $\mathrm{Lu}^{3+}$ приводит к образованию ватеритной структуры во всем образце.

В то же время образование фазы кальцита при $0.88<x<0.93$ в ортоборатах $\mathrm{La}_{0.98-x} \mathrm{Lu}_{x} \mathrm{Eu}_{0.02} \mathrm{BO}_{3}$, которые имеют структуру ватерита, происходит вначале в 
приповерхностных областях образца, а затем структура кальцита образуется во всем образце.

Ортобораты $\mathrm{La}_{0.98-x} \mathrm{Lu}_{x} \mathrm{Eu}_{0.02} \mathrm{BO}_{3}$ имеют высокую интенсивность свечения и могут быть использованы в качестве эффективных красных люминофоров для светодиодных источников света.

\section{Благодарности}

Авторы выражают благодарность ЦКП ИФТТ РАН за исследование морфологии образцов, а также их характеризацию методами ИК-спектроскопии и рентгенофазового анализа.

\section{Финансирование работы}

Работа выполнена в рамках госзадания ИФТТ РАН.

\section{Конфликт интересов}

Авторы заявляют, что у них нет конфликта интересов.

\section{Список литературы}

[1] C. Mansuy, J.M. Nedelec, C. Dujardin, R. Mahiou. Opt. Mater. 29, 6, 697 (2007).

[2] G. Blasse, B.C. Grabmaier. Luminescent Materials. SpringerVerlag, Berlin-Heiderberg (1994). 233 p.

[3] Jun Yang, Chunxia Li, Xiaoming Zhang, Zewei Quan, Cuimiao Zhang, Huaiyong Li, Jun Lin. Chem. Eur. J. 14, 14, 4336 (2008).

[4] Y.H. Zhou, J. Lin, S.B. Wang, H.J. Zhang. Opt. Mater. 20, 1, 13 (2002).

[5] J. Yang, G. Zhang, L. Wang, Z. You, S. Huang, H. Lian, J. Lin. J. Solid State Chem. 181, 12, 2672 (2008).

[6] С.З. Шмурак, А.П. Киселев, В.В. Синицын, И.М. Шмытько, А.С. Аронин, Б.С. Редькин, Е.Г. Понятовский. ФТТ 48, 1, 48 (2006).

[7] S.Z. Shmurak, A.P. Kiselev, N.V. Klassen, V.V. Sinitsyn, I.M. Shmyt'ko, B.S. Red'kin, S.S. Khasanov. IEEE Trans. Nucl. Sci. 55, 1-3, 1128 (2008).

[8] С.3. Шмурак, А.П. Киселев, Д.М. Курмашева, Б.С. Редькин, В.В. Синицын. ЖЭТФ 137, 5, 867 (2010).

[9] С.З. Шмурак, В.В. Кедров, А.П. Киселев, И.И. Зверькова. ФTT 55, 2, 336 (2013).

[10] С.З. Шмурак, В.В. Кедров, А.П. Киселев, Т.Н. Фурсова, И.М. Шмытько. ФТТ 58, 3, 564 (2016).

[11] A.A. Mazilkin, O.G. Rybchenko, T.N. Fursova, S.Z. Shmurak, V.V. Kedrov. Mater. Character. 147, 215 (2019).

[12] С.3. Шмурак, В.В. Кедров, А.П. Киселев, И.М. Шмытько. ФTT 57, 1, 19 (2015).

[13] С.3. Шмурак, В.В. Кедров, А.П. Киселев, Т.Н. Фурсова, И.М. Шмытько. ФТТ 57, 8, 1558 (2015).

[14] М.А. Ельяшевич. Спектроскопия редких земель. ГИТТЛ, M. (1953). 456 c.

[15] М.И. Гайдук, В.Ф. Золин, Л.С. Гайгерова. Спектры люминесценции европия. Наука, М. (1974). 195 с.

[16] J. Hölsä. Inorg. Chim. Acta 139, 1-2, 257 (1987).

[17] E.M. Levin, R.S. Roth, J.B. Martin. Am. Miner. 46, 9-10, 1030 (1961).
[18] G. Chadeyron, M. El-Ghozzi, R. Mahiou, A. Arbus, C. Cousseins. J. Solid State Chem. 128, 261 (1997).

[19] D. Santamaría-Pérez, O. Gomis, J. Angel Sans, H.M. Ortiz, A. Vegas, D. Errandonea, J. Ruiz-Fuertes, D. Martinez-Garcia, B. Garcia-Domene, André L.J. Pereira, F. Javier Manjón, P. Rodríguez-Hernández, A. Muñoz, F. Piccinelli, M. Bettinelli, C. Popescu. J. Phys. Chem. C 118, 4354 (2014).

[20] Wen Ding, Pan Liang, Zhi-Hong Liu. Mater. Res. Bull. 94, 31 (2017).

[21] WenDing, Pan Liang, Zhi-Hong Liu. Solid State Sci. 67, 76 (2017).

[22] С.3. Шмурак, В.В. Кедров, А.П. Киселев, Т.Н. Фурсова, И.И. Зверькова. ФТТ 62, 12, 2110 (2020).

[23] С.3. Шмурак, В.В. Кедров, А.П. Киселев, Т.Н. Фурсова, И.И. Зверькова, Е.Ю. Постнова. ФТТ 63, 7, 933 (2021).

[24] С.3. Шмурак, В.В. Кедров, А.П. Киселев, Т.Н. Фурсова, И.И. Зверькова, Е.Ю. Постнова. ФТТ 63, 10, 1615 (2021).

[25] R.S. Roth, J.L. Waring, E.M. Levin, Proc. 3rd Conf. Rare Earth Res. Clearwater, Fla. (1964). P. 153.

[26] C. Badan, O. Esenturk, A. Yelmaz. Solid State Sci., 14, $11-12,1710$ (2012).

[27] И.М. Шмытько, И.Н. Кирякин, Г.К. Струкова. ФТТ 55, 7, 1369 (2013).

[28] А.П. Киселев, С.3. Шмурак, Б.С. Редькин, В.В. Синицын, И.М. Шмытько, Е.А. Кудренко, Е.Г. Понятовский. ФТТ 48, 8,1458 (2006).

[29] Н.И. Стеблевская, М.И. Белобелецкая, М.А. Медков. Журн. неорган. химии 66, 4, 440 (2021).

[30] J. Guang, C. Zhang, C. Wang, L. Liu, C. Huang, S. Ding. Cryst. Eng. Commun. 14, 579 (2012).

[31] J. Zhang, M. Yang, H. Jin, X. Wang, X. Zhao, X. Liu, L. Peng. Mater. Res. Bull. 47, 247 (2012).

[32] Heng-Wei Wei, Li-Ming Shao, Huan Jiao, Xi-Ping Jing. Opt. Mater. 75, 442 (2018).

[33] R. Nayar, S. Tamboli, A.K. Sahu, V. Nayar, S.J. Dhoble. J. Fluoresc. 27, 251 (2017).

[34] S.K. Omanwar, N.S. Savala. Appl. Phys. A 123, 673 (2017).

[35] C.E. Weir, E.R. Lippincott. J. Res. Natl. Bur. Std.-A. Phys. Chem. 65A, 3, 173 (1961).

[36] A. Szczeszak, T. Grzyb, St. Lis, R.J. Wiglusz. Dalton Transact. 41, 5824 (2012)

[37] Ling Li, Shihong Zhou, Siyuan Zhang. Solid State Sci. 10, 1173 (2008).

[38] А.Г. Рябухин. Изв. Челябинского науч. центра 4, 33 (2000).

[39] W.C. Steele, J.C. Decius. J. Chem. Phys. 25, 6, 1184 (1956).

[40] Radha Velchuri, B. Vijaya Kumar, V. Rama Devi, G. Prasad, D. Jaya Prakash, M. Vithal. Mater. Res. Bull. 46, 1219 (2011).

[41] Cansin Badan, Okan Esenturk, Ayşen-Yılmaz. Solid State Sci. 14, 1710 (2012).

[42] D. Boyer, F. Leroux, G. Bertrand, R. Mahiou. J. NonCrystalline Solids 306, 110 (2002).

[43] J.P. Laperches, P. Tarte. Spectrochim. Acta 22, 1201 (1966).

[44] Jun Yang, Cuimiao Zhang, Lili Wang, Zhiyao Hou, Shanshan Huang, Hongzhou Lian, Jun Lin. J. Solid State Chem. 181, 2672 (2008).

[45] С.3. Шмурак, В.В. Кедров, А.П. Киселев, Т.Н. Фурсова, О.Г. Рыбченко. ФТТ 59, 1, 1150 (2017).

Редактор Т.Н. Василевская 